\title{
Review \\ Critical and sustainable fluxes: theory, experiments and applications
}

\author{
P. Bacchin ${ }^{(1)}$ P. Aimar ${ }^{(1)}$ and R.W. Field ${ }^{(2)}$ \\ (1)Laboratoire de Génie Chimique, Université Paul Sabatier, 118 route de Narbonne,
} 31062 Toulouse cedex, France

(2) Department of Engineering Science, University of Oxford, Parks Road, Oxford OX1 3PJ, UK

*Corresponding author. bacchin@chimie.ups-tlse.fr, Fax number : (33) 561556139

Over the last ten years, numerous membrane filtration data have been viewed in the light of the concept of critical flux. This concept, used in a number of different ways often without explicit redefinition, is here clarified both from a theoretical and from an experimental viewpoint. Also, a link is make with the sustainable fluxes. Also covered are the various methods of measurement and the influence of membrane and suspension properties on the critical flux. Over the same period of time, models have been developed to explain the observed behaviour. Those for stable colloidal suspensions are based on the existence of repulsive interactions between soft matter constituents. The assumptions and usefulness of various models are discussed. The concept of a critical concentration for phase transition is introduced into the theoretical discussion. For theoreticians and experimentalist, this and the clarified concept of a small set of critical fluxes will continue to provide a valuable framework. For membrane users dealing with most industrial process streams (mixtures and complex fluid) the concept of a sustainable flux (shown as being derived from critical flux) is of a great utility; above a certain key flux (dependent on hydrodynamics, feed conditions and process time) the rate of fouling is economically and environmentally unsustainable. For many, knowledge of the point below which no major irreversible fouling occurs (the critical flux) in a membrane separation will always be of greatest utility.

Keywords: fouling, critical flux, colloid, ultrafiltration, nanofiltration, microfiltration, reverse osmosis

\section{Introduction}

Flux reduction below that of the corresponding pure water flux (or more generally pure solvent flux) can be divided into two separate parts. Firstly concentration polarisation is a natural consequence of the selectivity of a membrane. This leads to an accumulation of particles or solutes in a mass transfer boundary layer adjacent to the membrane surface that affects the flux by a reduction in effective transmembrane pressure driving force (TMP) due to the osmotic pressure difference between filtrate and feed solution adjacent to the membrane surface. This phenomenon is inevitable, but is reversible with a reduction in TMP and hence flux.

Secondly there is fouling which may take the following forms:

- Adsorption : adsorption occurs when specific interaction between the membrane and the solute or particles exist. A monolayer of particles and solutes can grow even in the absence of permeation flux leading to an additional hydraulic resistance. If the degree of adsorption is concentration dependent then concentration polarisation exacerbates the amount of adsorption. 
- Pore blockage : when filtering, pore blockage can occur leading to a reduction in flux due to the closure (or partial closure) of pores.

- Deposit : a deposit of particles can grow layer by layer at the membrane surface leading to an important additional hydraulic resistance. This is often referred to as a cake resistance.

Accumulation (concentration polarisation) at the membrane surface cannot be avoided but a correct choice in operating conditions permits one to choose those conditions where the mass accumulation only has a minor effect on the process efficiency.

Working below critical flux can permit operation over long time periods without any significant deposition occurring (Fig. 1). The careful reader will have noticed that the word "significant" has been slipped in and this paper will also address the concept of sustainable flux later, this being particularly relevant for industrial processes.

Fouling can also change membrane selectivity and therefore the critical flux concept can have consequences for selectivity. Thus understanding the critical and sustainable positions will influence process optimisation with regard to both productivity and selectivity.

With regard to industrial processes the development of sub-critical membrane processes has lead to a reduction in energy consumption but there is a need for larger membrane surface area. So the decrease in running costs is partially off-set increased investment cost. Ideally there is the opportunity for sub-critical operation. Achieving or approaching such conditions has good prospects:

- Environmentally beneficial; there is lower energy consumption and less usage of chemical agents and therefore the operation is more environmentally friendly.

- Technically sound; sub-critical conditions yield a clean way of operation that can be more easily controlled. Ideally it allows one to work with a membrane that is not covered by fouling multilayers which drastically change the selectivity efficiency.

- Economically attractive; with membrane cost decreasing sub-critical membrane operation or near sub-critical operation will be attractive to both operators of membrane processes and suppliers who will increase sales volume.

Scientifically, the critical flux concept is now ten years old. Over the last ten years, a lot of studies have been realised on "critical flux" determinations for crossflow membrane filtration. As an illustration, Figure 2 shows the growing evolution over the last ten years of the number of publications in journals satisfying the research criteria "critical flux* and (fouling or membrane)". Data was taken from Science Citation Index in March 2005. In the same figure, the number of these papers as a percentage of those dealing with fouling in membrane science (satisfying the research criteria "fouling and membrane") is also plotted. This relates to the impact of the concept. In recent years, 10-20 papers per year were produced using the critical flux concept and this represents around $10 \%$ of the scientific production on fouling in membrane science. This research area is expanding and now represents a significant part of works dealing with fouling. These works have also a good impact factor: the 90 papers being cited 666 times over these years. Table 1 lists papers concerned with this concept that have had more than 30 citations. The first three of them corresponds to the first ones to define a critical flux in 1995.

This paper seeks to summarise the literature on "critical" flux especially with regard to colloidal filtration, to summarise methods of measurement and to refine and clarify usage of terms in order to maintain their utility. Such action is necessary because as Samuel Baker (1835-1902) wrote "A definition is the enclosing of a wilderness of idea within the wall of words" but as a contemporary noted "words are slippery and thought is viscous" (Henry Brooks Adams, 1838-1918). Slippage has occurred and the actual ideas being discussed obscured so it is timely to disentangle various concepts and in so doing to 
answer the questions, "Is the critical flux concept just a fashion or a useful concept?", and "What other related terms (e.g. sustainable flux) are now useful?"

\section{Critical flux concept : background and first definition}

This section provides some background information. It is intended to be neither a comprehensive review of fouling nor of Flux-TMP relationships.

An important characteristic of membrane operation, especially in UF/MF, is the limiting flux which corresponds to the maximum steady state flux achievable with a given solution or suspension Michaels [1]'Porter [2]. For this limit, further increases in TMP do not increase flux.

Broadly speaking the critical flux has been defined in two ways. Either as the flux at which the transmembrane pressure (TMP) starts to deviate from the pure water line (the strong form of critical flux) or as the first permeate flux for which irreversible fouling appears on the membrane surface. The critical flux can be generally defined as the "first" permeate flux for which fouling become predominant; being then well differentiated from limiting flux (the "last" flux reachable).

As a contextual introduction, some prior history and the birth of this concept are given below.

\subsection{State of the art leading to the critical flux concept}

Historically, the first publication giving the idea of a possible "threshold" flux when filtering a colloidal suspension has to be attributed to Cohen et al. [3] in 1986. In this publication, the authors noted that permeate flux obtained during reverse osmosis of ferric hydroxide was very high (and called this the "colloid flux paradox"). They advanced the idea that such a behaviour could be due to surface interaction between colloidal particles. In 1989, Mcdonogh et al. [4] pursued this idea and reported experiments with silica particles where permeate flux was affected by changes of ionic strength. This underlines the role played by surface interaction. In a 1994 review, Belfort et al. [5] detail fouling mechanisms and included in their discussion a section about colloid capture by a membrane which is however separated from the main one dealing with particle transport. They concluded that progress has been made in "identifying the importance of colloidal and particle fouling and the proper description of colloid-membrane interaction" but that there still exists a need to develop "quantitative understanding of the possible interactions that can occur between (...) particles in a complex process streams".

\subsection{First definitions and features}

In 1995, the first three papers to define the critical flux concept were published. Firstly a theoretical model proposed by Bacchin et al. [6], [7] balanced surface interaction, diffusion and convection. This gives a physical explanation for the "colloid flux paradox". When compared to other transport phenomena, surface interaction are shown to be responsible for fluxes which are well above the ones given with other transport phenomena (diffusion, shear induced diffusion and lateral migration) for particle size between 10 nanometers and 10 micrometers (Fig. 3). From this modelling, a critical flux is defined as "the flux below which no fouling occur" and its existence is theoretically proven and physically explicated by transport phenomena induced by surface interaction: the critical flux is the flux required to overcome repulsion and lead to the coagulation on the surface. This definition has the clear merit of being related to a physical mechanism and "criticality" is the point at which the repulsive barrier is overcome.

The second paper took a purely empirical approach. Field et al. [8] defined "a flux below which a decline of flux with time does not occur; above it fouling is observed". As shown in Figure 4, there are two forms of this flux: strong and weak. The strong form is the flux at which the transmembrane pressure (TMP) starts to deviate from the pure water line, which is of course linear. For the weak form, 
there is the assumption that there is very rapid fouling on start-up and so the flux-TMP relationship is below that of the pure water line. The critical flux (weak form) is the point at which this line becomes non-linear.

Thirdly Howell [9] depicted "a flux below which there is no fouling by colloidal particles" which allows then the definition of "sub-critical flux operation of microfiltration". In so far as this definition avoids reference to fouling by macromolecules that might also be present, and that their effect could increase with time, this definition can now be seen retrospectively, as a harbinger of the concept of a sustainable flux.

\subsection{Clarification and new definitions}

It is important before going further to clarify definitions of critical flux that will be linked to methods of measurements $(\S 3)$, experimental features $(\S 4)$ and theory $(\S 5)$. Above it was noted that the term critical flux had been used in mainly two ways, either as the flux at which the flux-transmembrane pressure (TMP) curve starts to deviate from linearity or as the first permeate flux for which irreversible fouling appears. Definitions have been given at different levels. Some are from a physical (deterministic) point a view (typically defined as the flux that leads to coagulation close to and then deposition upon the membrane) whilst others are from an experimental (naturalistic) point a view. The latter were typically defined as the flux leading to a first deviation from a linear variation with TMP.

A clarification will be first made in this section according to classical flux-TMP-fouling equations. Some further link to the theory will be seen in the modelling section. Generally, reduction in flux (or increase in pressure) for constant pressure (flux) operation is linked to a filtration law which can be seen as an integral form of the Darcy law in which different fouling mechanisms operate.

$$
J=\frac{\Delta P-\Delta \pi}{\mu\left(R_{m}+R_{a d s}+R_{\text {rev }}+R_{\text {irrev }}\right)}
$$

An osmotic pressure term, $\Delta \pi$, reduces the efficiency of the trans-membrane pressure. Furthermore, hydraulic resistance are added to the membrane resistance because of :

- $\quad$ surface or pore adsorption, $\mathrm{R}_{\text {ads }}$ (independent of solvent transfer)

- a fouling resistance driven by the filtered volume being reversible (eg possibly pore blinding, or cake deposit), $\mathrm{R}_{\text {rev }}$, or irreversible (possibly cake deposit or gel formation), $\mathrm{R}_{\text {irrev }}$.

This classification allows one to distinguish additional resistances (such as adsorption) that are independent of the pressure and permeate flux from fouling phenomena driven by the solvent transfer through the membrane. Fouling of the latter type can be reversible $\left(\mathrm{R}_{\mathrm{rev}}\right)$ or irreversible $\left(\mathrm{R}_{\text {irrev }}\right)$ when the pressure is decreased.

When considering these fouling mechanisms, the strong form of critical flux, $J_{\mathrm{cs}}$, has been developed to discriminate no fouling conditions (where $R_{m}$ is the only resistance in equation 1) from fouling conditions where other resistances also apply. It has been defined as the flux at which the fluxtransmembrane pressure (TMP) curve starts to deviate from linearity (Fig. 4). So with the assumption that osmotic pressure effects are negligible

$$
\begin{aligned}
& \text { for } \mathrm{J}<\mathrm{J}_{\mathrm{cs}}: J=\frac{\Delta P}{\mu R_{m}} \\
& \text { for } \mathrm{J}>\mathrm{J}_{\mathrm{cs}}: \quad J=\frac{\Delta P}{\mu\left(R_{m}+\left(R_{\text {rev }}+R_{\text {irrev }}\right)\right)}
\end{aligned}
$$

where at least one of $R_{\text {rev }}$ or $R_{\text {irrev }}$ is non-zero and when $R_{\text {ads }}$ is considered as negligible. 
The weak form of critical flux, $J_{\mathrm{cw}}$, has been used to distinguish operation below and above the point at which the performance is influenced by fouling phenomena that are driven by the solvent transfer through the membrane. Initially the additional term was applied only to adsorption occurring at the outset of filtration [8]. Later a distinction was made by $\mathrm{Wu}$ et al. [10] between very low fouling conditions and more significant ones, with this intermediate region being between, $J_{\mathrm{cs}}$ and $J_{\mathrm{cw}}$. However in this review the former definition is retained.

$$
\begin{aligned}
& \text { for } \mathrm{J}<\mathrm{J}_{\mathrm{cw}}: J=\frac{\Delta P}{\mu\left(R_{m}+R_{\text {ads }}\right)} \\
& \text { for } \mathrm{J}>\mathrm{J}_{\mathrm{cw}}: J=\frac{\Delta P}{\mu\left(R_{m}+R_{\text {ads }}+R_{\text {rev }}+R_{\text {irrev }}\right)}
\end{aligned}
$$

where at least one of $R_{\text {rev }}$ or $R_{\text {irrev }}$ is non-zero

We now define a new term "critical flux for irreversibility", $J_{\mathrm{ci}}$, to discriminate fouling with respect to its irreversibility. Above the critical flux for irreversibility, there are growing multi-layers of irreversible fouling in the boundary layer whereas below it only a concentration polarisation layer exists in all cases with an additional mono-layer of adsorbed species in some cases. When filtering macromolecules or colloidal dispersion, this critical flux is related to the coagulation of the dispersed phase close to the membrane surface, followed by deposition upon it. Accumulatted matter at the membrane undergoes a phase transition from a dispersed phase (concentration polarisation) to a condensed phase (multi-layer deposit).

The irreversibility form of the critical flux can be defined by :

$$
\begin{aligned}
& \text { for } \mathrm{J}<\mathrm{J}_{\mathrm{ci}}: J=\frac{\Delta P-\Delta \pi}{\mu\left(R_{m}+R_{\text {ads }}+R_{\text {rev }}\right)} \\
& \text { for } \mathrm{J}>\mathrm{J}_{\mathrm{ci}}: J=\frac{\Delta P-\Delta \pi}{\mu\left(R_{m}+R_{\text {ads }}+R_{\text {rev }}+R_{\text {irrev }}\right)}
\end{aligned}
$$

where $R_{\text {ads }}$ might include in-pore fouling or monolayer adsorption.

There is a theoretical foundation for the critical flux for irreversibility in the work of Bacchin et al. [7] accounting for colloidal surface interaction. This approach can also be found in the experimental analysis of Defrance et al. [11]' [12] who defined the "critical" flux as the flux below which the TMP remains stable and fouling is reversible. These authors say that before this flux fouling is due to pore plugging and adsorption but when it was exceeded TMP increased and did not stabilise due to cake formation at the surface.

Although the concept of critical flux was originally postulated as a method of avoiding fouling it is now seen by many as a concept related to the minimisation of fouling. Thus the useful concept of sustainable flux has recently evolved especially in the context of membrane engineering. Whilst having links with the concept of critical flux, a sustainable flux itself is not a critical flux. For mixtures (and this includes most industrial process streams) the concept of a sustainable flux is useful; above a certain key flux (dependent on hydrodynamics, feed conditions and process time) the rate of fouling is unsustainable. If there is a clear discontinuity in the rate of fouling as a function of flux then this point is very important from a practical point of view.

Three different definitions of critical flux were used above and these are summarised in Table 2. They relate to different patterns of flux-TMP-fouling behaviour. Various inter-relationships exist between the terms. For example when adsorption and osmotic pressure phenomena are insignificant and the fouling resistance is purely irreversible, then the strong form of critical flux and the critical flux for irreversibility are exactly the same (fig. 5 a). Secondly if adsorption (or other fouling phenomena independent of 
pressure) occurs but there is no osmotic effect then the weak form of critical flux and the critical flux for irreversibility are exactly the same (fig. 5 b). In those cases where osmotic pressure can not be neglected (eg colloidal and macromolecular filtration Fig. 5 c) then the critical flux for irreversibility is the only definition that is theoretically sound because a deviation from linearity might be the consequence of the osmotic pressure (which is a reversible phenomena). The irreversibility can be shown by [10] hysterisis in the flux-pressure relationship as flux is increased and decreased. Figures. $5 \mathrm{c}$ might also describe the behaviour of particulate systems, such as earlier work Benkahla et al. [13] on cake growth in the crossflow microfiltration of mineral suspensions. Often the critical flux for irreversibility $J_{\text {ic }}$ has been measured but $J_{\mathrm{cs}}$ or $J_{\mathrm{cw}}$ might also exist and an estimate would be of scientific interest.

\section{Methods of Measurement}

The critical flux has mainly been obtained from flux-TMP measurements often by flux or pressure stepping. Also observations have been deduced from particle mass balances and by direct observation through the membrane (DOTM). Various methods are introduced together with critical comments upon their implementation including the quality (accuracy and reliability) to price (experiment length and complexity) ratio of methods.

\subsection{Deductions from Flux-Pressure observations}

Flux-pressure experiments can be made either by imposing a flux and measuring a pressure or by imposing a pressure and measuring a flux. They have different advantages and inconveniences.

A constant pressure allows determination of a steady state flux (the filtration system is self regulated: fouling decreases the flux thus reducing rate of fouling) which lead to reliable results with no time dependance (if a sufficient duration for each pressure step is used). On the other hand, a constant flux leads in the presence of fouling phenomena to a continuously increasing pressure with running time because of a (quasi) constant fouling rate. The former method allows then determining steady state flux (and then steady state hydraulic resistance) whereas the second one is able to give for a given flux the fouling rate (the variation of the resistance with time). These methods are then fully complementary giving steady state data (needed to scale-up filtration process) whereas the second one gives dynamic data (often allowing to have an idea of the sustainability of fouling in the process).

In a general way, constant pressure experiment can be recommended when working with suspension showing few adsorption in order to reach intrinsic steady state permeate flux. On the other hand, constant flux experiments are adapted to reveal fouling phenomena with complex suspensions.

\subsubsection{Flux-pressure profile}

With a suitable value for the permeability of the membrane either constant pressure or constant flux operation can be used to determine the critical flux. However, for UF membranes of dilute feeds [10] found that it was very difficult to control the TMP at a low enough value to measure the strong form of the critical flux and therefore that constant flux operation was to be preferred. Constant flux operation (with measurement of TMP) is readily achieved by pumping the permeate. The TMP should remain constant with time at each flux, as any increase indicates fouling and therefore that the critical flux has been exceeded. Ideally the total resistance should be calculated at each step to check whether the resistance has remained constant.

Constant pressure experiments have also been used, for example, by Gesan-Guiziou et al. [14]. An indication of fouling is then given by flux decline. So with certain feeds permeate pumping is not essential but for very sensitive determination of critical flux constant flux operation is recommended 
because the sensitivity of the TMP measurement allows small changes due to any trace fouling to be detected. Another example in Fradin et al. [15] of constant pressure operation involved magnesium hydroxide suspensions and a sintered metal membrane. For critical flux operation, membrane conditioning was required. This involved operation of the membrane at a low flux and with a dilute suspension for a few hours prior to operation with feeds of interest. When membrane conditioning of this type is involved, any critical flux found is now best viewed as being a critical flux for irreversibility, $J_{\text {ic. }}$.

For both modes, the critical flux is the point where the flux-TMP relationship becomes non-linear. If flux-TMP gradient is lower than that of clean water but linear then this critical flux is of the weak form. Whilst reference was made to water, one could for UF/MF, but not RO, beneficially substitute buffer solution. The use of pure water can lead to very thick Gouy-Chapman double layers and an electroviscous resistance in the membrane pores. This effect can be effectively removed by using electrolyte (higher ionic strength).

It is important that the flux is initially sub-critical and then increased to the critical flux. If initially the flux is higher then irreversible fouling at the higher flux will affect any subsequent measurements. From figure 6a, Milcent et al. [16] concluded that the "critical flux" was $50 \mathrm{l} / \mathrm{m}^{2} \mathrm{~h}$. At 50 $1 / \mathrm{m}^{2} \mathrm{~h}$ TMP does appear to have stabilised however this graph cannot be used to determine $\mathrm{J}_{\text {crit }}$ without some crosschecking of resistance because the flux was previously much higher. Indeed if one examines the TMP curve one may note that there has been some irreversible fouling as TMP is much higher than when it was at this flux previously. For the lower crossflow velocity (Figure 6b) the value attributed to $\mathrm{J}_{\text {crit }}$ was given as $201 / \mathrm{m}^{2} \mathrm{~h}$ but the same reservations hold. Also there appears to be a slight increase in TMP at this flux which means it is above the critical flux. The values determined do relate to a significant change in behaviour but do not satisfy the definition of critical flux as originally defined. There is insufficient evidence to determine whether the fouling is reversible and so the values given can not be taken to be values of the critical flux for irreversibility. Repetition of the experiments approaching the flux values from below would have been of greater interest.

Although during flux stepping experiments, an increase in TMP at a given flux indicates fouling, the converse, namely an observably constant TMP at a constant flux, is not enough to prove sub-critical flux operation. For example, Persson et al. [17] claimed stable fluxes up to $110 \mathrm{l} / \mathrm{m}^{2} \mathrm{~h}$ but it can be seen from the flux-TMP profile (figure 7) that some fouling has occurred by $80 \mathrm{l} / \mathrm{m}^{2} \mathrm{~h}$. There can be a flux above the critical value at which pressure will appear to remain constant with time because the new steady-state is rapidly obtained. For this reason, resistance calculation at each point is recommended. Thus the essential determination of the linearity (or otherwise) of the flux-TMP relationship can be made

\subsubsection{Flux stepping and flux cycling}

The simplest form of this technique is a set of increasing pressure steps followed by a set of decreasing steps, eg Chen et al. [18]. They showed that above the "critical" flux a significant hysteresis occurred but the deviation from linearity was not made clear. The stepwise filtration procedure has been commonly used to determine "critical" filtration conditions for a variety of fluids eg Gesan-Guiziou et al. [19]'Kwon et al. [20]'Manttari et al. [21]. An identical step-by-step procedure but regulated on the permeate flux was used by $\mathrm{Wu}$ et al. [10]. They described two types of experiments. One is a series of increasing flux steps (eg Figure 6 in [10]), the other involves a series of up-and-down steps. The latter is a series of flux cycles and is illustrated in Figure 8. In the latter the sensitivity of the TMP measurement allows small changes due to any trace fouling to be detected. For example when examining the filtration of BSA solution with the 50k MWCO membrane (pH 7.4, 0.15\% w/w, Re 248) use was made of this procedure where flux was increased and then decreased to a previous value in a series of steps. The filtration process consisted of a series of steps during each of which a flux was specified and the TMP produced was recorded. At step 1 , once $\mathrm{J}_{1}$ was set and the process had reached a steady state (in this case 
it took $40 \mathrm{~s}$ ) the transmembrane pressure was recorded as $\mathrm{TMP}_{1}$. If this was the first step, the flux was then increased to a slightly higher value and the flux was again recorded in a similar fashion. After this step with a slightly higher flux ended, the flux was set back to $\mathrm{J}_{1}$ and another value of TMP was recorded as $\mathrm{TMP}_{1}{ }^{\prime}$. The difference between $\mathrm{TMP}_{1}$ and $\mathrm{TMP}_{1}{ }^{\prime}$ was called the deviation. If deviation equalled zero, it was presumed that no fouling had occurred. The flux was then increased to $\mathrm{J}_{3}$ before being moved back to $\mathrm{J}_{2}$. If the difference between $\mathrm{TMP}_{2}$ and $\mathrm{TMP}_{2}{ }^{\prime}$ was zero, it was presumed that no fouling had occurred. Fig 8 illustrates the flux, the TMPs and the deviation at each stage for the process. It shows that for the first three steps all the deviations were zero which means there was no fouling at all before the flux was $20 \mathrm{~lm}^{-2} \mathrm{~h}^{-1}$. Furthermore the calculated resistance was constant. Upto stage 7 the amount of fouling is close to the limit of detection.

As illustrated in Figure 8 the transition to irreversible fouling occurs either at the same point as the deviation from linearity or it occurs at a higher flux. Clearly a check of reversibility is required. This can be done using flux stepping but instead of steadily increasing the flux, the flux should be increased by two steps and then decreased by one and TMP measured at each step. If the TMP, when the flux is decreased, is not the same as when the flux was previously at that level, irreversible fouling has occurred and the critical flux for irreversibility has been exceeded. This technique has been used by Metsamuuronen et al. [22]. Their experiments were run for only 9 minutes, which is only sufficient to indicate "critical" flux. Half an hour is a more common length of time. Certainly it is worth checking that the critical flux indicated in short times is stable over longer periods of time. In most early works including that of some of the co-authors' this was not done. Some recent theoretical work indicates the importance of time especially for macromolecules and this point will be expanded upon later.

Critical flux obtained by mass balance (see section 3.3) are always inferior (around two times less) than the one obtained by analysing results of a flux step method. Whilst one may question the "critical" flux values obtained from profiles and deduce different values, there is a need for improved techniques (and clearer definitions) if different values are obtained by different people from the same data. A more accurate critical flux determination can be obtained by analysing the reversibility of the fouling for each step of pressure or flux. To this end the procedure of filtration with pressure steps composed of alternative increasing and decreasing step initiated by $\mathrm{Wu}$ et al [8] has been developed further by Espinasse et al. [23]. This last method allows continuous quantification of fouling reversibility so permitting very accurate measurement of critical flux of both types.

Espinasse et al. [23] realised experiments with alternative up and down pressure steps for which the steady state flux were measured (step principle in figure 9). By analysing these experiments, the authors dissociated the irreversible and reversible part of fouling for each pressure step i.e. continuously during the filtration. If reversible fouling is associated with the osmotic pressure contribution, then figure 10 shows an increase of osmotic pressure from the start of the filtration. However the increase due to the irreversible part of fouling was measured only above a flux of around $1410^{-6} \mathrm{~m} / \mathrm{s}$. This flux is the critical flux for irreversibility $\left(J_{\mathrm{ci}}\right)$. The behaviour corresponded to that shown in Figure 5c.

Whether fouling is reversible and hence whether the transition to irreversibility has been exceeded is readily determined by this technique but repetition of experiments is highly desirable. Clearly Defrance et al. [12] determined a point of very significant change in the experiments above $921 / \mathrm{m}^{2} \mathrm{~h}$ as shown by the data of Figure 11. Either as they suggest the increasing and decreasing fluxes (at lower fluxes) are not identical due simply to experimental error or there is a very minor component of irreversible fouling during initial operation. 
Another factor that may influence the transition to irreversibility is the flux-pressure history. If the flux is increased gradually to a given level, the cake can be much looser and more likely to re-disperse than if that same flux had been imposed immediately.

\subsection{Direct Observation through the Membrane (DOTM)}

In discussion some have suggested the term "cake formation flux". The cake formation flux cannot be measured directly using the flux-pressure relationship of $\S 3.1$ as the changes might well not be attributable to cake. With other evidence it would be reasonable for this to be the cause of sudden changes and large increases in TMP. This question can partially be answered by results from DOTM (Direct Observation Through the Membrane). In DOTM, a microscope is used to look through an Anopore membrane, which is transparent when wet. Deposition of particles on the membrane surface (or their absence) can be observed. Li et al. [24]' [25] have used this technique and shown that the variations in pressure caused by deposition can be very small. This can be seen in figure 12. Thus the point of first deposition is not the point of large changes in resistance.

Clearly DOTM is a very sensitive way of detecting particle deposition but it is restricted to transparent membranes. Nevertheless this technique where applicable is the only one that can be used for direct observation of the initial deposit on the membrane. Also it has to be noted that these direct observation have always been made on particle of a relatively large size (circa $10 \mu \mathrm{m}$ in diameter). Although the use of UV observation may in the future permit the observation of smaller particles of a few microns in diameter.

Electron micrographs have proven the non-existence of deposit on a membrane after sub-critical operation [18]. Direct observation during the formation of deposit on membrane have been realised by $\mathrm{Li}$ et al. in 1998 [24]. These observations have proven the appearance of a deposit above the critical flux.

\subsection{Mass Balance}

By monitoring the concentration of particles in the outlet stream, Kwon et al [20] measured a critical flux based on a particle mass balance. The adsorption of particles in the system was measured by measuring the concentration when there was no flux. The idea is that any reduction in particle outlet concentration not caused by passive adsorption/adhesion is caused by deposition. Once the deposition rate at several fluxes had been found a graph of flux against deposition rate was plotted. The critical flux was then found by extrapolation; it is the flux at which the deposition rate is zero. This could be expected to relate to a "cake formation flux". However the critical fluxes were also measured using TMP increases at constant flux and found to be up two times larger. However, the flux-TMP relationship seems to have been ignored and it is not linear below the alleged critical fluxes. For example in figure 13, where $0.816 \mu \mathrm{m}$ diameter latex was being filtered, the authors have said that critical flux is around $1201 / \mathrm{m}^{2} \mathrm{~h}$ for all pore sizes but by $80 \mathrm{l} / \mathrm{m}^{2} \mathrm{~h}$ all the profiles have become non-linear which suggests the critical flux is at least $40 \mathrm{l} / \mathrm{m}^{2} \mathrm{~h}$ too high. So the point of transition that was determined will have corresponded to a different phenomena.

Gesan-Guiziou et al [14] claim they found their critical flux from a mass balance and TMP stepping simultaneously but they do not say whether these values agreed or if they used an average of the two. Bowen et al. [26] have used a similar technique. They found the fractional deposition after 4 hours of operation at several different fluxes. By plotting these, they could extrapolate to find the flux at which there was no deposition but they did not find a critical flux for all the membranes they used. The mass balance technique does not distinguish between strong and weak forms of critical flux and gives no information about reversibility per se. It should be used in conjunction with another technique. Also it 
must be remembered that whilst it is suitable as a complementary technique for particulates, it is not directly applicable to macromolecules where a measurable quantity of solute will accumulate (polarise) near the membrane in the concentration polarisation layer.

\subsection{Determination by fouling rate analysis}

As noted by Le Clech et al. [27], a zero rate of TMP increase may never be obtained during trials with real and synthetic sewage. Thus use of the flux-step or any other method to determine critical flux will yield a result that it may not exist. In their work the result is that if it exists, the value is less than $2 \mathrm{~lm}^{-2} \mathrm{~h}^{-}$

1. The useful results from experiments in this area relate to the rate of fouling. Significant differences above and below clearly defined fluxes have been found as illustrated in Figure 14. These points of change are significant and relate to the operational and economic sustainability of a membrane process. So as already indicated the term sustainable flux $J_{\text {sus }}$ will be more appropriate if a distinction is being made between low and high fouling rates. It is conceivable that the rate of fouling approach will identify both a value $J_{\text {sus }}$ and a critical flux. Indeed referring back to Figure 5, three points of change might be significant: two critical fluxes $\left(J_{\mathrm{cs}}\right.$ or $J_{\mathrm{cw}}$ and $\left.J_{\text {sus }}\right)$ as illustrated in that figure and at a higher flux a value of $J_{\text {sus. }}$.

\subsection{Comparison of techniques for critical flux measurement}

The various measurement techniques have different advantages and disadvantages : a summary is given in table 3. According to the definition given in section 2, the weak and strong form of critical flux can be defined by a deviation from water flux line. Irreversibility form of critical flux can be fully determined by methods with continuous up-and-down flux or pressure steps. Mass balance method could be a useful complement to these methods with a determination of deposited mass. However, for complex suspension, the analysis of the criticality via fouling rate, obtained through when operating with the flux step method have shown interesting perspectives for submerged membrane bioreactor in Jefferson et al. [28]. This method has potential to characterise fouling in others systems.

\section{Experimental features}

First experimental highlights of the critical flux concept were by Field [8] and Howell [29] who used a wide range of different colloidal suspension (yeast, dodecane-water emulsion and calcium carbonate slurry) which shows the breadth of interest for sub-critical operation of microfiltration. Experimental determination of critical flux realised on clays with different ionic strength have proven the important link between the critical flux value and suspension stability so underling the role taken by particles repulsion in the concept of critical flux [30]. Many studies have since proven the existence of a "critical" flux (the inverted commas are used to show that the values determined might relate to the sustainable flux rather than the critical flux) and have determined its value with different fluid and filtration conditions. These works have been realised with various kind of fluid suspension from "model or lab" fluid to more complex suspensions related to industrial applications as listed below.

The wide range can be viewed as consisting of three subsets (colloidal dispersion, macromolecular solution and complex fluid) for which the increasing level of complexity can explain the difficulties in reaching accurate and reliable critical flux value:

Colloidal particles 
- Gold sol : Madaeni [31]

- Silica particles : [10]'[18]'Huisman et al. [32]

- Latex : [14]'[19]'[20]'[24]'Li et al. [25]'[23]'Espinasse [33]'Kwon et al. [34]'Vigneswaran et al. [35]

- Clays : Bacchin et al. [30]'Cabassud et al. [36]'Hamachi et al. [37]'Kwon et al. [38]

Macromolecular solution

- Proteins

- lactalbumin : Howell et al. [39]'Vyas et al. [40]

- Myoglobin : [22]

- $\gamma$-lactoglobulim and IgG : [39]'Chan et al. [41]

- lysozyme : Chan et al. [42]

- Bovine Serum Albumine : [10]'[41]'[42]'Chen [43]'De Zarate et al. [44]

- Natural Organic Matter (NOM) or humic substances : [26]'Aoustin et al. [45]'Seidel et al. [46]'Yuan et al. [47]

- Emulsion : [8]

Complex fluid

- Yeast cells : [10]'[22]'[25]'Chang et al. [48]'Sur et al. [49]

- Skimmed milk : [19]'Al Akoum et al. [50]'Gesan-Guiziou et al. [51]'Gesan-Guiziou et al. [52]'Grandison et al. [53]'Youravong et al. [54]

- Water and waste water : Chapman et al. [55]'Choksuchart et al. [56]'Vera et al. [57]'Vera et al. [58]

- Lactic acid broth : [16]'[17]'Carrere et al. [59]

- Bioreactors sludge : Defrance et al. [11]'[12]'Bouhabila et al. [60]'Chang et al. [61]'Cho et al. [62]'Choo et al. [63]'Fane et al. [64]'Gander et al. [65]'Jefferson et al. [66]'Madaeni et al. [67]'Ognier et al. [68]

- Pulp and paper mill : [21]'Huuhilo et al. [69]'Manttari et al. [70]

Table 4 summarises the operating conditions for these principal determinations of "critical" flux. Objectives of most of these publications were focused on the determination of fouling mechanisms so as to have a good choice of operating conditions. The way determinations can be made and the tools develop to experimentally access "critical" flux has been covered in $\S 3$. The sensitivity "critical" flux to operating conditions is now reviewed (suspensions properties $\S 4.1$, hydrodynamics $\S 4.2$ and membrane properties $\S 4.3)$ and the consequences on process productivity and selectivity is detailed $\S 4.4$.

\subsection{Effect of suspension properties on critical flux}

\subsubsection{Suspension stability}

As soon as surface interaction was highlighted as being mainly responsible for the critical flux of colloidal suspensions [7] numerous works were undertaken to study the effect of suspension properties. Principally these are $\mathrm{pH}$, which changes the solute charge, and ionic strength that varies the surface repulsion through charge screening. Globally an increase in $\mathrm{pH}$ above the isoelectric point (IEP) gives an increase in the critical flux. By way of illustration, firstly it has been found that there is an increase in the weak form of critical flux from 60 to $1051 / \mathrm{h}^{2}$ for myoglobin as $\mathrm{pH}$ is increased from 7 to 8 (Metsammuren et al. 2002 [22] in Table 4). Secondly for silica the following rise was found: circa 145 to $195 \mathrm{l} / \mathrm{h} / \mathrm{m}^{2}$ as $\mathrm{pH}$ increased from 3 to 5 (Chen et al. 1997 [18] in table 4). A minimum in the critical flux 
has also been determined for BSA suspension for a $\mathrm{pH}$ near the IEP as presented in figure 15 (Chan and Chen 2001 [42]). Consistent with this, it has been observed with whey protein concentrate and sodium caseinate suspensions (Youravong et al. 2002 [54]) that there is an increase in critical flux for both protein suspensions with increasing $\mathrm{pH}$.

Regarding ionic strength, an increase of ionic strength below the critical concentration for coagulation decreased the critical flux both in clays suspension [30] and for latex particles (Kwon et al. 2000 [20], Espinasse 2003 [33]). Also addition of electrolyte decreased the critical flux for sodium caseinate with a more pronounced influence for $\mathrm{CaCl}_{2}$ than for $\mathrm{NaCl}$. These experiments directly illustrate the role of the ionic strength and the $\mathrm{pH}$ on the repulsive surface interaction that can explained through DLVO theory. They underline again the direct correlation between the stability of the suspension and the critical flux.

Surface hydrophobic interaction has also been shown to be important in more complex suspensions. The effect of $\mathrm{Ca}^{++}$concentration on critical flux has been underlined during NOM nanofiltration (Seidel and Elimelech 2002 [46]). The formation of Ca-NOM binding leads to a change in interaction between NOM macromolecules: the stability is decreased by a change in conformation when calcium is added which exposes the hydrophobic part of NOM. As a consequence a decrease in the critical flux is observed.

Changes in electrostatic interaction are not always the cause of suspension instability. For example an increase of $\mathrm{pH}$ beyond a threshold value in a membrane bioreactor used for denitrification (Ognier et al. 2002 [68]) resulted in an important decrease in critical flux. This resulted in the deposition of carbonate calcium precipitate on the membrane. The mechanism of precipitation or crystallisation of a solute can be seen as resulting from the presence of a solute with low stability. So again the important decrease in critical flux results from suspension instability.

\subsubsection{Suspension concentration}

A lot of studies show a decrease in the critical flux when the suspension concentration rises. As an example, Gesan Guisiou et al. 2002 [14] observed a rapid decrease of the critical flux with increasing concentration of suspensions of latex. From 0.4 to $2 \mathrm{~g} / 1$, critical flux values decreased from 140 to 47 $1 / \mathrm{h} / \mathrm{m}^{2}$. For higher concentrations the critical flux was almost constant at around $301 / \mathrm{h} / \mathrm{m}^{2}$ for concentrations from 3 to $8 \mathrm{~g} / \mathrm{l}$. The same trend was observed for latex suspensions by Kwon et al. 2000 [20]. However the plotting of the permeate flux as a function of the logarithm of the concentration is not linear and so does not satisfy the film model. As a consequence neither the film nor the gel model can explain the mass accumulation. Variation of diffusion coefficient or viscosity (Aimar et al. [71]) and the presence of surface interaction Bacchin et al. [7] can be responsible for these discrepancies. As explained in earlier work (Field et al. [72]) a constant surface concentration is not to be expected. The effect of concentration in a complex suspension exhibited similar behaviour but sometimes with only slight decreases in critical flux with increasing concentration of bacterial cells in fermentation broth [17] or with activated sludge concentration [67] as illustrated with figure 16.

\subsubsection{Suspension size}

The effect of the particle size on the critical flux is difficult to determine experimentally as it is necessary, for an accurate analysis, to have particles with different size but the same surface properties. A study [20] was made with polystyrene latex particles of seven different sizes from 0.1 to $10 \mu \mathrm{m}$. Experimental determination of critical flux both based on the TMP increase for constant flux experiments and on a mass balance on particles in the retentate showed a minimum in the critical flux for particles size of about $0.2 \mu \mathrm{m}$ (figure 3). The value of critical flux observed is superior for particles of $0.1 \mathrm{~mm}$ (fig. 4). This trend (minimum of critical flux for size around $100 \mathrm{~nm}$ ) was found theoretically by Harmant et al. [73] and explained (fig. 17) by a coupling of different critical flux mechanisms of diffusion (higher for smaller particles) and surface interaction (higher for bigger particles). Such a minimum can also be related to the transition between the formation of gel layer (for small particles) and a deposit (for bigger 
particles) [74]. Experiments made by Li et al.(2000) [25] for larger particles also showed an increase of critical flux with particle size. These results will be compared to back-transport mechanisms in the section dedicated to model analysis $\S 5$.

\subsection{Effect of hydrodynamics on critical flux}

Hydrodynamics at the membrane surface have a major influence on variations in critical flux values: an increase in the strength of the hydrodynamics being synonymous with a critical flux rise. Furthermore, the sensitivity of critical flux to hydrodynamic conditions can explain the distribution of critical fluxes (and then of fouling) along a membrane surface.

\subsubsection{Hydrodynamic and global critical flux}

Tangential flow at the membrane surface induces a variation of critical flux which has typically been expressed as a power law of the Reynolds number in numerous papers dealing with critical flux. Such a trend is found in all studies dealing with effect of the cross-flow velocity on critical flux but a common exponent for this power law can not be deduced from these works. It has to be noted that a large cross flow velocity can cause only a small increase in critical flux if the pressure drop along the membrane surface becomes significant [67]. For the same TMP, the transmembrane pressure at the inlet of the membrane surface when the velocity and hence feed-side pressure gradient are high is itself high. This leads to a local permeate flux which can be superior to the critical value and hence local fouling.

Experiments have also been made with different hydrodynamic promoters: cross rotational and vibratory shear enhanced processes (Al Akoum et al. 2002 [50], Huuhilo et al. 2001 [69]), gas sparging (Sur and Cui 2001 [49], Cabassud et al. 2001 [36], Chang and Fane 2000 [48], Bouhabila et al. 1998 [60]), washing period (Defrance and Jaffrin 1999 [12]), agitator-induced flushing (Ahn et al. [75]).

A critical ratio linking the permeate flux and the hydrodynamics has theoretically to be related to the mass transfer coefficient or boundary layer thickness [7]' [76]. The critical ratio is then a critical Péclet number $(J \delta / D)$. Gésan-Guisiou et al. [51] expressed their hydrodynamic criteria in terms of a critical wall shear stress; the experimental results on ultrafiltration of skimmed milk showed a linear variation of critical flux and wall shear stress (figure 18). The slope of this line, which has been found to $0.951 \cdot \mathrm{h}^{-1} \cdot \mathrm{m}^{-2} \cdot \mathrm{Pa}^{-1}$ for skimmed milk [51] and $181 \cdot \mathrm{h}^{-1} \cdot \mathrm{m}^{-2} \cdot \mathrm{Pa}^{-1}$ for latex particles [14], represents a critical ratio independent of hydrodynamic conditions and only a function of suspension properties. The intercept with $\mathrm{x}$-axis is interpreted as a critical erosion shear stress below which a critical flux does not exist for a given solution-membrane combination. These two last approaches using a critical Péclet number or a critical ratio "flux over wall shear stress" are convergent as the wall shear stress and boundary layer thickness can be theoretically linked through the Fanning friction factor.

\subsubsection{Critical flux distribution along the membrane}

Critical flux can be reached preferentially at certain points along a membrane surface. A distribution of fouling distribution along a membrane has already been discussed by different authors well before the critical flux concept was evolved (Gourgues et al. [77]) but can be interpreted by the critical flux concept. Experimental illustration of this behaviour has been observed during filtration near subcritical flux showing an important distribution of deposited mass along the membrane surface during biomass filtration for a membrane without spacers (figure 19 from [62]) or during desalination by reverse osmosis with spacer filled channels (Schwinge et al. [78]).

Such a trend can be fully explained by a distribution of critical flux along the membrane surface which is theoretical explained by the fact the real critical number is not the critical flux but a critical Peclet number [7]. Indeed, the boundary layer thickness grows along the membrane leading to a decrease in mass transfer coefficient. So if one considers that there is a constant critical Peclet number then it follows that there is a decrease in critical flux from the membrane inlet to outlet. This distribution explains why a cake grows from the outlet where hydrodynamic conditions and then mass transfer coefficient are unfavourable to the inlet [74]' [76]. Critical Peclet number can then be explained by the 
trends illustrated by figure 19. These last results emphasize the role of a critical number Peclet to describe critical fouling conditions in tangential filtration. It has to be noted that recent models integrate the critical flux and its distribution along the membrane in submerged hollow fiber modules to optimise the fibre length and radius (Chang et al. [79]).

\subsubsection{Analogy in dead end filtration}

In the absence of tangential flow along the membrane (i.e. dead end filtration) a critical flux can not be observed if the critical factor is a critical wall shear stress. However, a critical filtered volume ([73], Bacchin et al. [80]) has been found for dead-end filtration of certain fluids. Indeed, for dead end filtration of a colloidal suspension, a deposit appears on the membrane only after a given filtered volume (the critical filtered volume). Such a concept presents the same phenomena with regard to the formation of an irreversible coagulated deposit as when, in cross-flow filtration, the critical flux for irreversibility is not exceeded. Thus for true colloidal suspensions there is a link to dead-end operation.

\subsection{Effect of membrane properties on critical flux}

Membrane properties such as porosity and pore size (or molecular weight cut-off) have been experimentally investigated in addition to the effect of the membrane materials properties (surface charge or hydrophilic effect).

\subsubsection{Effect of membrane porosity and cut-off}

The geometric structure of the membrane (porosity, cut-off, pore shape ...) has been shown to be important for critical flux. Wu et al. [10] observed for a PES membrane a decrease of the critical flux when the membrane cut-off is increased (Table 4). As proposed by the authors, the change in critical flux could be the difference in surface properties (such as charge) but could also be the results of a change in local porosity and hence in local permeate velocity. The latter would modify locally the balance between drag force and surface interaction responsible for the critical flux. This effect might be particularly important for macromolecules. Recently during the ultrafiltration of colloidal latex suspension it was observed that the initial permeability of tubular ceramic membranes has little effect on the critical flux value [14]. However, experiments realised on a membrane pre-coated with an irreversible deposit induced an important decrease in critical flux.

Experiments have been recently performed on microsieves i.e. membrane with well-defined pore made by controlled etching. Bromley et al. [81] have shown five fold higher critical flux with slotted pores that with a circular pores. These last results clearly indicate the impact of the local structure at the membrane surface on the critical flux. Furthermore, other experiments with microsieves realised by Kuiper et al. [82] with circular pores but different porosity have shown that porosity can play an important role in the development of the cake layer at the membrane surface. For high porosity i.e. pore very close to each other, steric hindrance can occur between particles and prevented their deposition on the whole membrane surface. Even if critical flux is exceeded the deposit can not develop on the whole surface. Such a system might well have a critical flux for irreversibility, $J_{\mathrm{ci}}$, in excess of a conventional critical flux $J_{\text {cs }}$ or $J_{\text {cw. }}$.

A membrane with a higher porosity will have a better distribution of the permeate flux on the porous surface (lower value for local maximum permeate flux) and should lead to an increased global (averaged over the whole surface) critical flux.

\subsubsection{Effect of membrane materials}

Huisman et al. [32] ran experiments on silica filtration using three membranes having the same cut-off but made with different membrane materials (titania, zirconia and $\alpha$-alumina). No noticeable difference in the value of critical flux was observed even when membrane zeta potential was changed 
from positive to negative. The effect of a membrane surface being hydrophobic or hydrophilic or even the effect of a membrane cleaning did not show consequences for the determination of critical flux [21]. The only difference noted in favour of hydrophilic membranes [22] can be explained by the fact that the hydrophilic membrane exhibited higher porosity which can be the cause of a higher value in critical flux (as detailed in the previous paragraph). Chan and Chen [42] emphasise this conclusion in a study focused on the pre-cake formation which showed evidence of the importance of membrane morphology for the limiting mechanisms only during sub-critical experiments. A time-lag for a first appearance of fouling resistance was introduced dependent on the kinetics of protein aggregation and aggregate deposition. Finally it has to be noted that the critical flux for irreversibility was defined as the permeate flux above which a multilayer fouling occurs $(\S 2.3)$. Thus almost by definition membrane surface properties can have only little effect on the value of $J_{\text {ci }}$.

\subsection{Consequences of critical flux on process efficiency}

\subsubsection{Consequences on productivity}

As already discussed above, critical flux is a concept of importance to optimise filtration productivity. Indeed, fouling leads to a loss of productivity. Fouling may only be reduced by the adoption (if applicable) of membrane back-washing adapted (additional cost and lost in energy and/or permeate production) or an increase in shear at membrane surface (additional energy cost due for example to increased cross-flow velocity). The possibility open by sub-critical operation is then very challenging. A lot of works cited above have shown results of filtration without fouling and hence no loss in productivity over a long period of time. One of the main applications of sub-critical operations is the filtration of bioreactors sludge which can work at low flux. Numerous publications have been made in this area. As an example, Gander et al. 2000 [65] report that there is evidence from MBRs to support the critical flux hypothesis as many submerged plate and frame plants run at a trans-membrane pressure inferior to 0.4 bar with no noticeable steady-state flux decline.

\subsubsection{Consequences on selectivity}

Some papers use the determination of a critical flux to improve the fractionation by avoiding an additional rejection due to a deposit on the membrane. Studies on membrane selectivity have soon been used to verify the concept of critical flux i.e. the presence of a deposit on the membrane surface. However, Chen et al. [18] who was expecting an increase of rejection above or below the critical flux, observed no variation in rejection have been observed in this paper whether the membrane was operated above or below the critical flux. They explain this trend by two concomitant phenomena: an increase in flux can both be responsible for a deposit and then an additional resistance to the solute transfer (increase in rejection) and the cause of the increase of solute concentration at the membrane (decrease in observed rejection). Gésan-Guisiou et al. 1999 [51] note an important increase in retention of both $\beta$-lactaglobulin and $\alpha$-lactalbumin when operating at fluxes above the critical flux when filtering skimmed milk. These results were confirmed at different value of tangential flow and explained by authors as the consequences of an irreversible deposition of casein micelles, micro-organisms and entrapped or retained soluble proteins at the membrane surface. In 2002, Chan et al. [41] showed in a study combining fouling and selectivity determination during filtration of a solution of two proteins, a minimum of observed rejection in the smaller protein near the critical flux (Fig. 20) : the initial decrease of rejection with permeate flux could be explained by the increase of the membrane concentration and the following increase by the appearance of the deposit leading to an additional resistance for protein transfer. From these results, as underlined by Howell et al. 2002 [39], controlled flux operation can be a solution to operate high fractionation level with membrane processes by taking advantage of the fact that when the flux increases the rejection of high molecular weight decreases (because of the fouling layer) whilst that of lower molecular weight materials decreases (because of the polarisation concentration). Knowledge of critical flux concept seems to be essential to achieve high degree of separation with membrane processes. 


\section{Theoretical development and explanation}

The cause for the existence of a critical flux are based on back transport mechanisms which can be surface interaction or hydrodynamic phenomena such as lateral migration or shear induced diffusion (figure 2 and 16). Lateral migration or shear induced diffusion have led to model development well before the appearance of the critical flux concept. The review of 1994 [5] has been complemented by Li et al. [25]. We will therefore focus our discussion of recent models on the effect of surface interaction during ultrafiltration which are well adapted to describing colloidal fouling.

\subsection{Mass balance in a boundary layer}

The first "modified film model", as it was call by the authors, was developed by McDonogh et al. (1989) [4]. Surface interactions in the boundary layer are accounted for through the force of repulsion due to osmotic pressure caused by the accumulation of ions between charged planes. This model describes the gap between the film model due to surface interaction and allows one to calculate the rise of steady state flux induced by an increase of zeta potential. These results are compared to steady state flux measurements. The same approach was developed in 1995 by Buffham et al. [83] in a model where the boundary layer assumptions was avoided by using the modified film model with a Berman axial flow (Berman [84]) and a mass balance along the channel section. Although this work includes, the notion of a metastable equilibrium indicating whether particle deposition is more or less likely, the term "critical" is intentionally avoided. The authors cite the reason as being: "there does not appear to be a critical phenomenon in the sense that a very small change in permeation rate causes the concentration profile to change from one for which deposition would be most unlikely to one for which deposition is almost certain". It has to be noted that this definition is now be used to depict a critical flux. In Bowen et al. [85], improvements are made in the way surface interaction act on mass transport: the effect of the surface interaction is taken into account through the variation of the collective diffusion coefficient accounting for multiple interactions between particles in a cell model Bowen et al. [86]. On the other hand, the osmotic pressure at the membrane surface is considered as a boundary condition of the problem avoiding a specific assumption for the wall concentration. However a parabolic concentration profile is imposed. This work does not put in light any critical phenomena. Jonsson et al. [87] in 1996 develop the same kind of model based on a depiction of the effect of surface interaction through a thermodynamic force due to the osmotic pressure gradient in a cell model accounting for multi-interactions. The model is developed in a boundary layer thickness and with a boundary condition based on the osmotic pressure at the membrane. The transition between polarisation concentration and deposit or gel on the membrane is explained as the consequence of the fact that the concentration at the membrane can reach a critical volume fraction for which the osmotic pressure has a maximum. The paper indicates that "the operating conditions under which the critical precipitation concentration (the gel or cake concentration) is reached can also be calculated" but no results were presented in this work. The same year BHATTACHARJEE ET AL. [88] included the effects of concentrated and interacting solutes in the convection-diffusion equation via a structure factor for interacting particles. This model allows then a realistic description of the behaviour of concentrated solutions near a membrane. However all calculations were made for volume fractions at the membrane too low to determine critical fouling conditions. More recently a modified film model with a two dimensional flow (Berman) was published byBacchin et al. [74]. The boundary condition was given by the osmotic pressure at the wall but a criteria for deposition was added giving a cake resistance when a critical osmotic pressure was reached. This model allows then the depicting of a critical flux and of the cake growing at the membrane surface (figure 21) and validates the more accurate concept of critical Peclet number [7]' [76] (§5.3). 


\subsection{Force equilibrium and Lagrangian approaches}

Also the fouling can be described through a mechanical approach based on a force balance on a particle (Lagrangian approach). Petsev et al. [89] published in 1993 a theoretical model based on a force equilibrium accounting for the surface interaction force acting on a particle in a body centred cubic or hexagonal geometry. The balance of this force with the permeate drag force in a dead end filtration law allows one to define the concentration profile above the membrane. A critical time is introduced to define the moment at which coagulation occurs on the membrane: "the hydrodynamic drag force, ..., tends to compress the particle layer, so that again at a given moment coagulation can occur". In 1994, Palecek et al. [90] developed a simplified equilibrium between the drag force on the proteins associated with the filtrate flow and the intermolecular repulsive interactions between the proteins in the bulk solution and those in the protein deposit on the surface of the membrane. This work was compared to experimental results of steady state flux obtained when filtering protein at $\mathrm{pH}$ 's away from the isoelectric point. However, this model needs to have an assumption on the distance between the protein and the membrane to estimate the limiting permeate flux. Harmant et al. [91] [73] develop a model based on the construction of layers of particles during dead end filtration (Figure 17). These constructions respect the balance between convective, diffusive and surface interaction force estimated in a hexagonal geometry. It is shown that above a critical filtered volume the sum of the drag force exerted on the accumulated layer lead to the coagulation of the first layer on the membrane.

In 1999 Bowen et al. [92] and later [93] proposed a model with a finite element approach calculating the force between a spherical colloidal particle and a cylindrical membrane pore accounting for the hydrodynamic force (resulting from permeation but not that from cross flow) in 2 dimensions and for the surface interactions. They found that a potential barrier exists at the pore entrance preventing a particle from entering the pore. Critical values of pressure gradients across the membrane pore have then been calculated. Kim et al. [94] developed recently a similar modelling (small differences are in the pore geometry (slit-shaped pore versus cylindrical pore) and in the calculation procedures)) but accounting for Brownian diffusion. A "critical filtration velocity " (similar to the critical flux concept) is again defined (figure 22) when diffusion is not accounted. However, at this time, this kind of simulation is limited to one particle at a pore entrance; the effect of particle-particle interaction is not accounted.

\subsection{Deposition rate modelling}

Another kind of model is based on the writing of the total mass flux continuity (with convective, diffusive and interactive mass flux) and using a boundary condition of perfect sink on the solid surface (nil concentration at the interface). The basic assumption is that all particles arriving at the collector surface are irreversibly and quickly captured and disappear from the system. Such a boundary condition originally applied by Smoluchowski [95] to describe fast coagulation and later used for determination of the stability ratio by Verwey et al. [96] is often used to solve deposition problems (Adamczyk et al. [97]). These kind of models differ from models based upon steady state mass balance ( $§ 5.1)$, wherein the mass flux is nil, in the way they can describe the variation of the mass transfer (the deposition rate) versus operating conditions.

Such a model has been developed [7] to describe the deposition problem during ultrafiltration fouling. This approach allows determination of the operating conditions promoting deposition on the one hand and no fouling on the other. Operating conditions are described through a Peclet number combining in one expression the effect of permeate flux and cross flow velocity (through the boundary layer thickness) and in the second expression the stability of the suspension. A critical Peclet number is then defined to border the fouling and no fouling zones:

$$
P e_{\text {crit }}=\frac{J_{\text {crit }} \delta}{D_{0}}=\ln \left(\frac{V_{B}}{\delta}\right)
$$


where $\mathrm{J}_{\text {crit }}$ is the critical flux, $\mathrm{D}_{0}$ the diffusivity at infinite dilution of the suspension, $\delta$ is the boundary layer thickness for mass transfer induced by the cross flow velocity and $\mathrm{V}_{\mathrm{B}}$ the potential barrier due to repulsive interaction which can be link to DLVO theory. This approach with boundary layer assumptions was developed by Song et al. [98] for a channel using a Bermann velocity profile. This paper underlines the important interplay between classical transport phenomena and interaction mechanisms but does not comment on critical phenomena for filtration.

\subsection{Models analysis}

These different studies have lead to important progress in the consideration of a new transport phenomenon to explain fouling in membrane processes: namely surface interaction. Today this has to be considered as important as molecular diffusion, shear induced diffusion and lateral migration. It is interesting to note that even very different modelling approaches (mass balance, force model or deposition rate) have lead to similar descriptions of critical conditions for filtration - the aggregation of the colloidal suspension at the membrane (Table 5). Physically, the critical flux can then be linked to the permeate flux and the respective drag force needed to overcome the repulsive barrier generated by interactions existing between colloidal particles. Above this critical value of the permeate flux, aggregation occurs in the suspension at the membrane surface leading to a multilayer deposit. The term critical has a scientific "semantic" significance here : critical is already used when surface interaction controls an aggregation phenomena - critical concentration for coagulation - [95] or for the critical deposition concentration Van de Ven [99] for the deposition kinetics on a collector. In these area, the term "critical" corresponds to the fact that the system shift from repulsive interaction between particles (dispersed matter - stable state) to attractive interaction (aggregate - unstable state) when a critical electrolyte concentration is added. In the same way, the critical flux represent the flux above which the accumulated mass at the membrane shift from repulsive interaction (dispersed matter - polarized layer) to attractive interaction (condensed matter - deposit) [100].

It has to be noted that the critical flux concept is sometimes used for larger particles (around $10 \mathrm{um}$ ) that are large relative to colloid suspensions. However, the mechanisms responsible for this phenomena are then essentially shear induced diffusion or lateral migration as predicted by comparison of the effect of various transport phenomena on the critical flux (fig. 4). When not processing colloidal suspensions the term "critical" loses a part of its significance.

Experimental results of critical flux observed by direct observation of mass accumulation through the membrane for latex particles and yeast cells (size superior to $3 \mu \mathrm{m}$ ) [25] were compared to calculation of shear induced diffusion and showed good agreement for larger particles (6 and $12 \mathrm{um}$ ). However for 3 $\mu \mathrm{m}$, the experimental critical flux was well above the one calculated. This difference can be explained by surface interaction which can generate for colloidal suspension a higher flux than those calculated using classical models (diffusion, shear induced diffusion and lateral migration) as seen in fig. 2. These results confirm the fact that in moving from 1 to $10 \mu \mathrm{m}$ the main phenomena for particle transport shifts from surface interactions to hydrodynamic causes.

The strength of the surface interaction models is their ability to explain the effect of suspensions properties such as $\mathrm{pH}$ or ionic strength which take a role in determining particle interaction and so control the formation of fouling layers. Critical operating conditions can then be theoretically deduced from physico-chemical properties of suspension. Their main weakness is the new degree of complexity and the inability to provide direct predictions (above all for complex fluids) from microscopic properties of the suspension (size, zeta, ionic strength...). One of the causes for this discrepancy can be that the theory on concentrated soft matter suspensions is not fully predictive. 


\section{Perspectives}

\section{1. $\quad$ Development of tools for engineers}

The main limit of the critical flux concept is its complexity: its experimental determination is difficult and the concept is not easy for engineers to use as a tool in process developement. It is then necessary to develop both experimental and theoretical tools allowing an accurate predictive determination of its impact on the process.

It is necessary to develop experimental procedures standardising critical flux determination. As seen above, determination of critical flux when realised by different methods can lead to important difference in the critical flux value. Progress in this area could come from the development of miniaturised and standardised filtration procedures with automated flux or pressure stepping allowing a continuous determination of the degree of irreversibility of the fouling. In this way, it will be possible to achieve accurate determination allowing, for a given suspension, to discriminate between membranes and to have a value which can be a parameter of importance for a process development.

On another hand, it is necessary to develop numerical tools for predicting a critical flux and its consequences on the process control. As seen above, the main difficulty comes from theory to describe concentrated properties of colloidal suspensions : a direct prediction (above all for complex fluid) based on microscopic properties of the suspension (size, zeta, ionic strength...) seems improbable as the theory on concentrated suspensions is not fully predictive in itself. An interesting perspective could then come from the determination of macroscopic properties of the suspension (osmotic pressure [87], sedimentation coefficient, rheology) which could be properties of importance to feed into models in order to have a fully prediction of filtration behaviour. These properties could then be reference data in the same way that liquid/vapor equilibrium is the reference data for prediction of distillation operations. However, one can think that these properties, which can seem absolutely necessary, will not be sufficient in all filtration cases mainly because of multiple source of heterogeneity in the membrane process [101]. The only solution to scale up the process might then come from expert systems feed both with data on the suspension and the membrane and with additional data illustrating experience of critical flux determinations.

\subsection{Development of sustainable membrane technology}

The critical flux approach has opened up interesting perspectives particularly sub-critical flux operations or close to this. Conditions close to will have reduced membrane back-washing and cleaning. This kind of operation has the quality required of a sustainable technology as less chemicals and less energy are needed. However, such an operation is running with low productivity (low permeate flux) and economic considerations might judge that this extensive production as not intensive enough. With the cost of membranes decreasing and the awareness towards sustainable technology growing, sub-critical operation of membrane processes is more and more likely.

\subsection{Development of high separation membrane technology}

The critical flux concept is of importance when a high degree of separation is required. Below the critical flux, no multilayer deposit cover the membrane surface and then the selectivity of the process is always control by the membrane. Above the critical flux, a deposit can act as a new separator leading to a change in selectivity $(\S 3.5)$. High separation membrane technology shows interesting perspectives in biotechnology and biogenetics applications. Such processes will have to run under critical filtration conditions in order to keep the original separative quality of the membrane 


\subsection{Membrane surface engineering}

Recent studies shows that critical flux can be linked to the structure and morphology of the membrane surface: local conditions on the membranes both in term of porosity or surface charge can play an important role on the macroscopic measurement of critical flux Bacchin et al. [102]. Some works, realised with microsieves, show the importance of pore shape [70] and pore distribution on the critical flux value : local permeate flux can be well above the ones determined with a homogeneous porous surface leading to important inaccuracy in the critical flux determination. From this consideration, one can think that an optimizing of the membrane surface could maximise the critical flux. Theoretically, the link between the membrane structure and morphology and the critical flux will have to be studied to account for the effect of local conditions on the macroscopic measure of the critical flux. The depicting of membrane with an homogeneous porous surface can be too restrictive for a membrane surface showing discrete porosity with different pore shape and a possible connectivity between pore. Such development could be at the basement of design of membrane micro and nanostructure.

\subsection{Critical flux concept boundary and limit}

The critical flux concept is often limited by the formation of the first layer on the membrane surface which limits the importance of the critical flux. The study of mechanisms preceding critical flux will have to be examined : the multilayer formation is preceded by a monolayer which can have its own kinetics [42] Such works will allows a better understanding of mechanisms underlined by Yuan et al. [103] :"a humic acid deposit or cake begins to form on those regions of the membrane that have been first covered by an aggregate. The rate of cake growth approaches zero at a finite filtrate flux, similar to the critical flux concept developed for colloidal filtration". It is necessary to run experiment and develop model accounting for both critical phenomena and kinetically controlled phenomena as adsorption or metastable phase transition. These kind of studies are need to understand well the weak form of critical flux which are present in the majority of industrial process leading to a sudden rise in pressure after long duration without fouling in sub-critical filtration as found with protein [41], bioreactors sludge [27]'[62] or lactic acid fermentation broth [59]. Likewise complexity should be allowed for elsewhere ; models for fouling are too much focused on one fouling mechanism and then used for suspensions with a size range. The effect of hydrodynamic phenomena such as shear induced diffusion and lateral migration will have to be fully compared to the effect of surface interaction in order to offer a good description for particles particularly in the size range 1 to $10 \mu \mathrm{m}$.

\section{Conclusions}

At the beginning, the concept of critical flux was of interest to depict fouling of "model" fluids. However, since these first works, the critical flux concept has been applied to complex fluids of relevance in numerous application domains $(\S 3$ : biotechnology - fermentation broth, waste water treatment -pulp and paper mill, bioreactors sludge or food industry - baker's yeast, skimmed milk).

From an experimental point of view, specific procedures have been and are always developed to give an accurate determination of the critical flux. Numerous experimental works allow one to generally depict the effect of the three data set involved in a separation operation : membrane properties, process conditions and fluid properties. At this time, review of paper show that critical flux determination could be useful to choose optimised operating conditions, to characterise the efficiency of hydrodynamic or to discriminate membrane efficiency. These works show the interest in critical flux determination both for the fouling control and for obtaining a high selectivity rate in avoiding deposit on the membrane. Critical flux filtration has then given scientific arguments to process filtration at low flux "low pressure ultrafiltration and nanofiltration". On a theoretical hand, surface interaction relative to colloidal 
suspension has been proposed as the main responsible of the existence of a critical flux. Model focused on the depicting of the coagulation of particles on the membrane have proven the theoretic existence of the critical flux even with very different approach. These models are not fully predictive but allow understanding the effect of soft matter suspensions properties on the critical flux.

From theses works, the original concept of critical flux (commonly admitted as separating conditions of no-fouling to fouling conditions) can be refined. A definition introducing critical flux as the flux traducing the transition between monolayer fouling (concentration polarisation, adsorption, pore blocking) to multilayer deposit (cake formation) is proposed to generalise the concept. This was labelled as $J_{c i}$, the critical flux for irreversibility. Experimental development and theoretical studies around the critical flux concept opens up interesting perspectives in numerous fields such as for the development of tools for process control, the development of sustainable membrane technology or highly separative membrane technology, but also for the control of the colloidal deposit structure or for membrane surface engineering.

The concept of critical flux involves specific work for the development of experimental tools, for theoretical models and for applications to an increasing range of ultrafiltration or microfiltration processes. More than a fashion, critical flux will be a powerful tool to control membrane fouling by colloidal suspension in $\mathrm{MF} / \mathrm{UF} / \mathrm{NF}$.

\section{Acknowledgements}

We have benefited over the years from stimulating conversations with many but would particularly like to mention Roger BenAim, Tony Fane and John Howell. 


\section{$\underline{\text { List of Tables }}$}

Table 1 Papers on the concept of a critical flux with more than 30 citations.

Table 2 Definitions of Critical Flux forms

Table 3 Methods of Measurement for Critical Flux: a comparison

Table 4 Features experiments on critical flux measurements

Table 5 Different models used to describe the effect of surface interactions on the fouling (presented following the date of publication). 
Table1 Papers on the concept of a critical flux with more than 30 citations.

\begin{tabular}{c|c}
\hline Publications & $\begin{array}{c}\text { Number of citations } \\
\text { since its publication }\end{array}$ \\
\hline \hline Field et al.1995 [8] & 118 \\
\hline Howell 1995 [9] & 75 \\
\hline Bacchin et al.1995 [7] & 62 \\
\hline Li et al. 1998 [24] & 49 \\
\hline Chen et al. 1997 [18] & 42 \\
\hline Bacchin et al. 1996 [30] & 35 \\
\hline Wu et al. 1999 [10] & 32 \\
\hline \hline
\end{tabular}


Table 2. Definitions of Critical Flux forms.

\begin{tabular}{|c|c|c|c|c|}
\hline Definitions & Abbrev. & \multicolumn{2}{|c|}{ Discrimination between } & Determination based on \\
\hline Strong form of critical flux & $\mathrm{J}_{\mathrm{cs}}$ & No fouling & Any kind of fouling & \multirow{2}{*}{$\begin{array}{c}\text { Linearity of flux-TMP } \\
\text { variation }\end{array}$} \\
\hline Weak form of critical flux & $\mathrm{J}_{\mathrm{cw}}$ & $\begin{array}{l}\text { Fouling independent } \\
\text { of solvent transfer }\end{array}$ & $\begin{array}{l}\text { Fouling driven by } \\
\text { solvent transfer }\end{array}$ & \\
\hline $\begin{array}{l}\text { Critical flux for } \\
\text { irreversibility }\end{array}$ & $\mathrm{J}_{\mathrm{ci}}$ & Reversible fouling & Irreversible fouling & Irreversibility \\
\hline Sustainable flux & - & Sustainable flux & No sustainable flux & Rate of fouling \\
\hline
\end{tabular}


Table 3. Methods of Measurement for Critical Flux: a comparison

\begin{tabular}{|c|c|c|c|c|}
\hline Method & Advantages & Disadvantages & Form measured & Suitability \\
\hline $\begin{array}{l}\text { Flux-pressure profile: } \\
\text { deviation from linearity } \\
(\S 3.1 .1)\end{array}$ & Simplicity & $\begin{array}{l}\text { Can be subjective. } \\
\text { No link with reversibility }\end{array}$ & $\begin{array}{l}\text { Strong and weak } \\
\text { form } J_{\mathrm{cs}}, J_{\mathrm{cw}}\end{array}$ & $\begin{array}{l}\text { Feeds with low osmotic } \\
\text { pressure }\end{array}$ \\
\hline $\begin{array}{l}\text { Flux or pressure vs time: } \\
\text { flux stepping }(\S 3.1 .2)\end{array}$ & $\begin{array}{l}\text { With up and down steps, } \\
\text { fouling hysteresis found. } \\
\text { Resistance should be } \\
\text { determined for each } \\
\text { step. }\end{array}$ & $\begin{array}{l}\text { Unlike flux cycling, } \\
\text { points of transition to } \\
\text { irreversibility can be } \\
\text { missed }\end{array}$ & $\begin{array}{l}\text { Strong and weak } \\
\text { form } J_{\mathrm{cs}}, J_{\mathrm{cw}}\end{array}$ & $\begin{array}{l}\text { Feeds with low osmotic } \\
\text { pressure; if correction is to } \\
\text { be made for osmotic } \\
\text { pressure flux cycling is to } \\
\text { be preferred. }\end{array}$ \\
\hline $\begin{array}{l}\text { Flux or pressure vs time: } \\
\text { flux cycling }(\$ 3.1 .2)\end{array}$ & $\begin{array}{l}\text { Rigorous when } \\
\text { allowance made for } \\
\text { osmotic pressure }\end{array}$ & $\begin{array}{l}\text { Time consuming and } \\
\text { complex }\end{array}$ & $\begin{array}{l}\text { All forms } J_{\mathrm{cs}}, J_{\mathrm{cw}} \text { and } \\
J_{\mathrm{ci}}\end{array}$ & All kinds of feed \\
\hline $\begin{array}{l}\text { Direct Observation } \\
\text { through the Membrane ( } \S \\
\text { 3.2) }\end{array}$ & $\begin{array}{l}\text { Direct observation of } \\
\text { flux giving deposition. } \\
\text { Potential for measuring } \\
J_{\text {ci }} \text { yet to be exploited. }\end{array}$ & $\begin{array}{l}\text { Limited to particulate } \\
\text { feeds and membranes that } \\
\text { are transparent when wet. }\end{array}$ & $\begin{array}{l}\text { Linkage to } J_{\mathrm{cs}}, J_{\mathrm{cw}} \text { or } \\
J_{\mathrm{ci}} \text { not obvious, but } \\
\text { value determined is } \\
\text { significant. }\end{array}$ & Particulate feeds. \\
\hline Mass balance $(\S 3.3)$ & $\begin{array}{l}\text { Linked to a } \\
\text { complementary } \\
\text { parameter, the deposited } \\
\text { mass. }\end{array}$ & $\begin{array}{l}\text { Needs to be used in } \\
\text { conjunction with another } \\
\text { method. }\end{array}$ & $\begin{array}{l}\text { Linkage to } J_{\mathrm{cs}}, J_{\mathrm{cw}} \text { or } \\
J_{\mathrm{ci}} \text { not obvious, but } \\
\text { value determined is } \\
\text { significant. }\end{array}$ & Particulate feeds \\
\hline $\begin{array}{l}\text { Determination by fouling } \\
\text { rate analysis } \\
(\S 3.4)\end{array}$ & $\begin{array}{l}\text { If a flux for "no fouling" } \\
\text { is not found then } \\
\text { determination of } \mathrm{d} P / \mathrm{d} t \\
\text { (under fixed fluxes) may } \\
\text { identify a point of } \\
\text { sustainable flux. }\end{array}$ & $\begin{array}{l}\text { Can be subjective. } \\
\text { No link with reversibility }\end{array}$ & $\begin{array}{l}\text { Strong and weak } \\
\text { form } J_{\mathrm{cs}}, J_{\mathrm{cw}}\end{array}$ & All feeds \\
\hline
\end{tabular}


Table 4. Features experiments on critical flux measurements

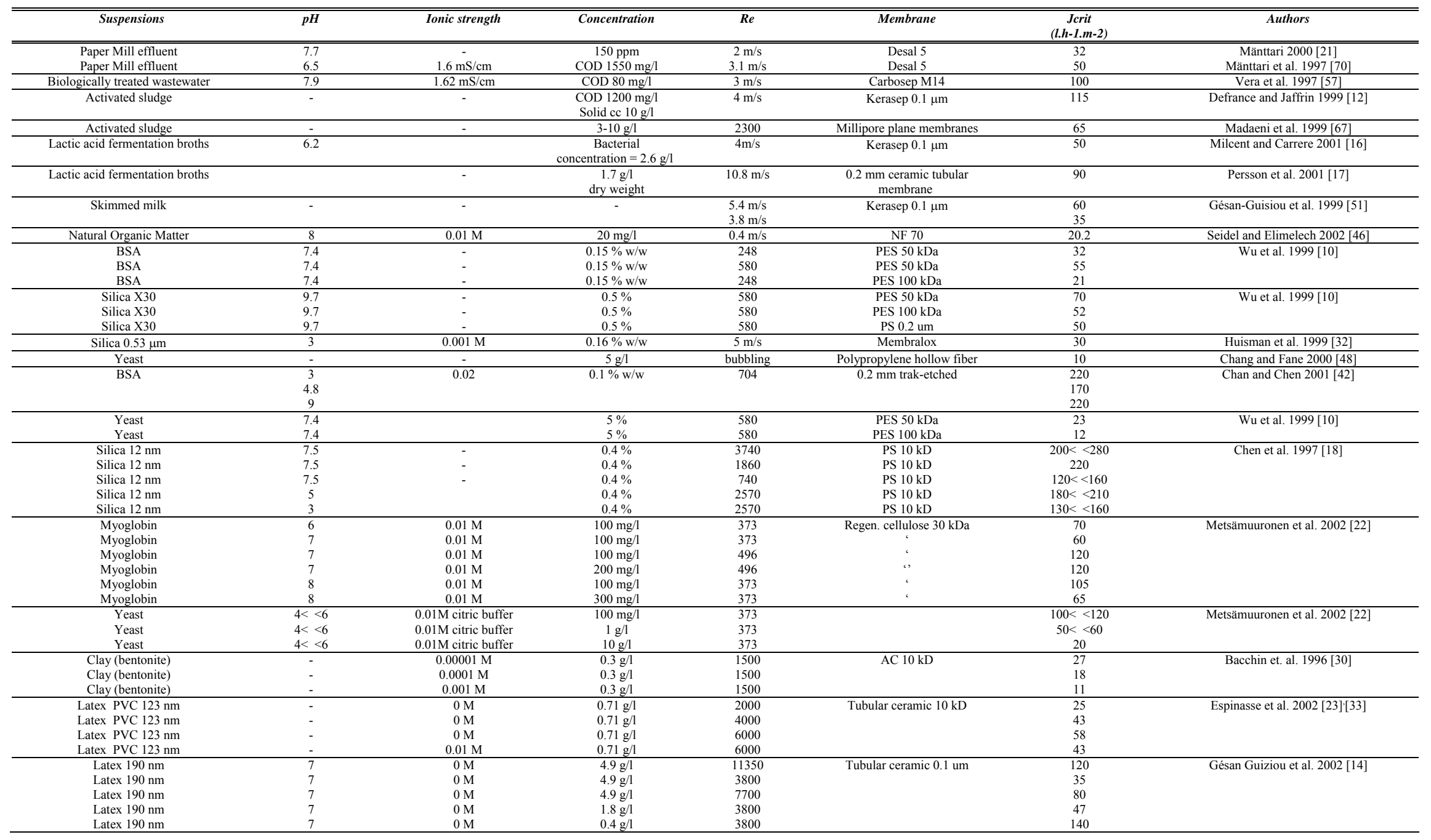


Table 5. Different models used to describe the effect of surface interactions on the fouling (presented following the date of publication).

\begin{tabular}{|c|c|c|c|c|c|c|c|c|c|}
\hline \multirow[b]{2}{*}{ Authors } & \multirow[b]{2}{*}{$\begin{array}{c}\text { Ref. } \\
\text { Num } \\
\text { ber }\end{array}$} & \multirow[b]{2}{*}{ Type } & \multirow[b]{2}{*}{ Diffusion } & \multicolumn{4}{|c|}{ Transport phenomena } & \multirow[b]{2}{*}{ Main assumptions } & \multirow{2}{*}{$\begin{array}{l}\text { Explication for } \\
\text { critical conditions }\end{array}$} \\
\hline & & & & $\begin{array}{c}\text { Interaction } \\
\text { induced } \\
\text { diffusion } \\
\end{array}$ & $\begin{array}{c}\text { Surface } \\
\text { interaction }\end{array}$ & Convection & cross-flow & & \\
\hline McDonogh et al. 1989 & [4] & $\begin{array}{l}\text { Mass } \\
\text { balance }\end{array}$ & $-D \cdot \nabla c$ & & $-\frac{D}{k T} \cdot c \cdot \nabla V$ & $+J . C$ & $\begin{array}{l}\text { Boundary } \\
\text { layer assum. }\end{array}$ & Wall concentration & No \\
\hline Petsev et al. 1993 & [89] & $\begin{array}{c}\text { Force } \\
\text { equilibrium }\end{array}$ & & $\begin{array}{c}\text { Interaction } \\
\text { induced force }\end{array}$ & & + Fconv & & $\begin{array}{l}\text { Dead end filtration } \\
\text { Wall volume fraction }\end{array}$ & $\begin{array}{l}\text { Critical time for dead end } \\
\text { filtration }\end{array}$ \\
\hline $\begin{array}{l}\text { Palecek and Zydney } \\
1994\end{array}$ & [90] & $\begin{array}{c}\text { Force } \\
\text { equilibrium }\end{array}$ & & & + Fint & $+F c o n v$ & & $\begin{array}{l}\text { Interactive force calculated at a } \\
\text { given distance to the interface } \\
\text { Absence of cross flow force }\end{array}$ & No \\
\hline Bacchin et al. 1995 & [7] & Deposition & $-D \cdot \nabla c$ & & $-\frac{D}{k T} \cdot c . \nabla V$ & $+J . C$ & $\begin{array}{l}\text { Boundary } \\
\text { layer assum. }\end{array}$ & Perfect sink & critical flux \\
\hline $\begin{array}{l}\text { Buffham and } \\
\text { Cumming } 1995\end{array}$ & [83] & $\begin{array}{l}\text { Mass } \\
\text { balance }\end{array}$ & $-D . \nabla c$ & & $-\frac{D}{k T} . c . \nabla V$ & $+J . C$ & $+v_{x y} \cdot c$ & Wall concentration & Metasble equilibrium \\
\hline $\begin{array}{l}\text { Song and Elimelech } \\
1995\end{array}$ & [98] & Deposition & $-D \cdot \nabla c$ & & $-\frac{D}{k T} . c . \nabla V$ & $\begin{array}{l}+v_{x y} \cdot C \\
+ \text { lift velocity }\end{array}$ & & Perfect sink & No \\
\hline $\begin{array}{l}\text { Jonsson and Jonsson } \\
1996\end{array}$ & {$[87]$} & $\begin{array}{c}\text { Mass } \\
\text { balance }\end{array}$ & & $-D(\phi) . \nabla c$ & & $+J . C$ & $\begin{array}{l}\text { Boundary } \\
\text { layer assum. }\end{array}$ & Steady state & $\begin{array}{c}\text { Operating conditions for } \\
\text { critical precipitation } \\
\text { concentration }\end{array}$ \\
\hline Bowen et al. 1996 & {$[85]$} & $\begin{array}{c}\text { Mass } \\
\text { balance }\end{array}$ & & $-D(\phi) . \nabla c$ & & $+J . C$ & $+v_{x y} \cdot c$ & $\begin{array}{l}\text { Permeate flux at the membrane } \\
\text { Parabolic concentration profile }\end{array}$ & No \\
\hline $\begin{array}{l}\text { Harmant and Aimar } \\
1998\end{array}$ & [91] & $\begin{array}{c}\text { Force } \\
\text { equilibrium }\end{array}$ & $\begin{array}{l}\text { diffusive } \\
\text { force }\end{array}$ & & + Fint & + Fconv & no cross flow & Dead end filtration & Critical accumulated mass \\
\hline $\begin{array}{l}\text { Bowen et al. } 1999 \\
\text { Bowen and Sharif } \\
2002\end{array}$ & $\begin{array}{l}92] \\
{[93]}\end{array}$ & $\begin{array}{l}\text { Lagrangian } \\
\text { approach }\end{array}$ & & & + Fint & +Fhydro & $2 D$ & $\begin{array}{l}\text { One particle in dead end } \\
\text { filtration }\end{array}$ & $\begin{array}{l}\text { Critical pressure gradient } \\
\text { and Critical filtration velocity }\end{array}$ \\
\hline $\begin{array}{l}\text { Bhattacharjee et al. } \\
1999\end{array}$ & {$[88]$} & $\begin{array}{c}\text { Mass } \\
\text { balance }\end{array}$ & & $-D(\phi) . \nabla c$ & & $+J . C$ & & $\begin{array}{l}\text { Multiple interaction and radial } \\
\text { distribution function accounted }\end{array}$ & \\
\hline Bacchin et al. 2002 & [74] & $\begin{array}{c}\text { Mass } \\
\text { balance }\end{array}$ & & $-D(\phi) . \nabla c$ & & $+J . C$ & $+v_{x y} \cdot c$ & Steady state & Critical flux \\
\hline Kim and Zydney 2004 & [94] & $\begin{array}{l}\text { Lagrangian } \\
\text { approach } \\
\end{array}$ & $\begin{array}{l}\text { Stochastic } \\
\text { force }\end{array}$ & & + Fint & + Fhydro & $2 D$ & $\begin{array}{l}\text { One particle in dead end } \\
\text { filtration }\end{array}$ & Critical filtration velocity \\
\hline
\end{tabular}



Figure 1. Fouling mechanisms on a membrane a) below critical flux b) above critical flux. Above critical flux, fouling (or more exactly multilayer fouling driven by permeation) becomes predominant.

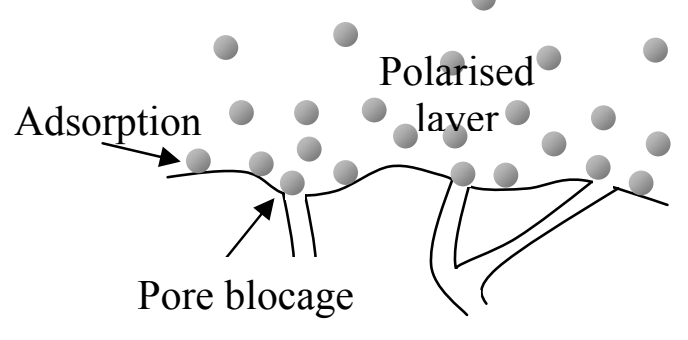

a)

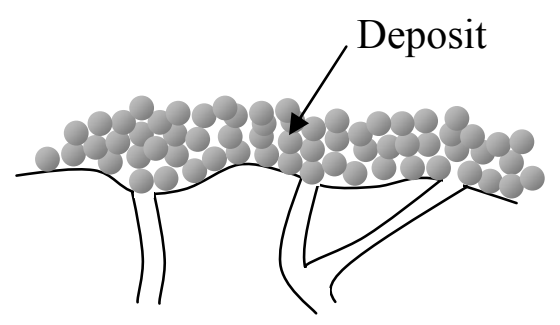

b) 
Figure 2. Numbers of publications around critical flux concept and their relative percentage to paper dealing with fouling in membrane science last ten years

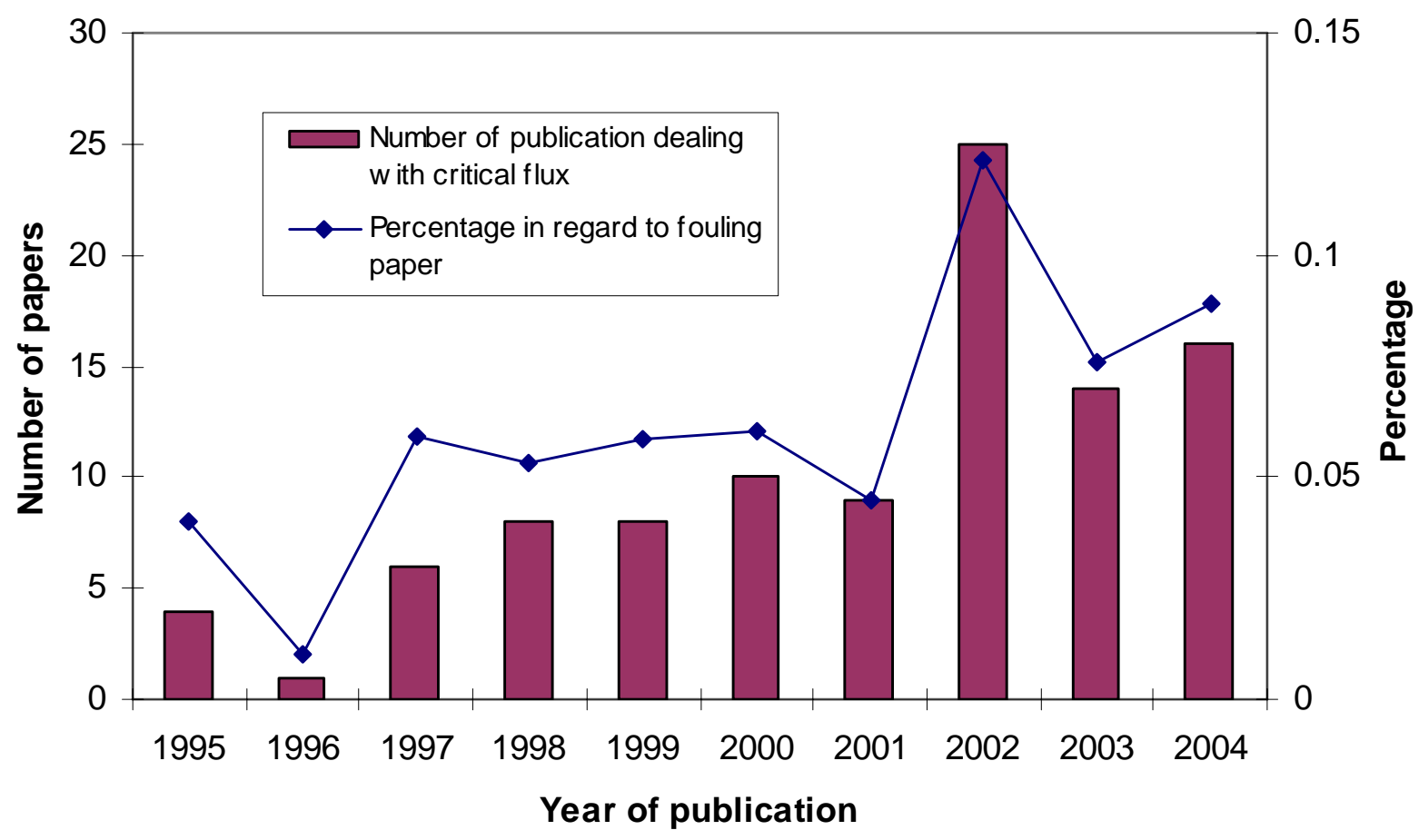


Figure 3. Calculation of a critical flux induced by colloidal surface interaction and comparison with flux being obtained accounting for Brownian diffusion, shear induced diffusion, lateral migration and tubular pintch effect (from [7]). Calculations (Reynolds number of 1500) are compared to experimental value of flux for colloids (symbols). Surface interaction can be an explanation for "colloid flux paradox".
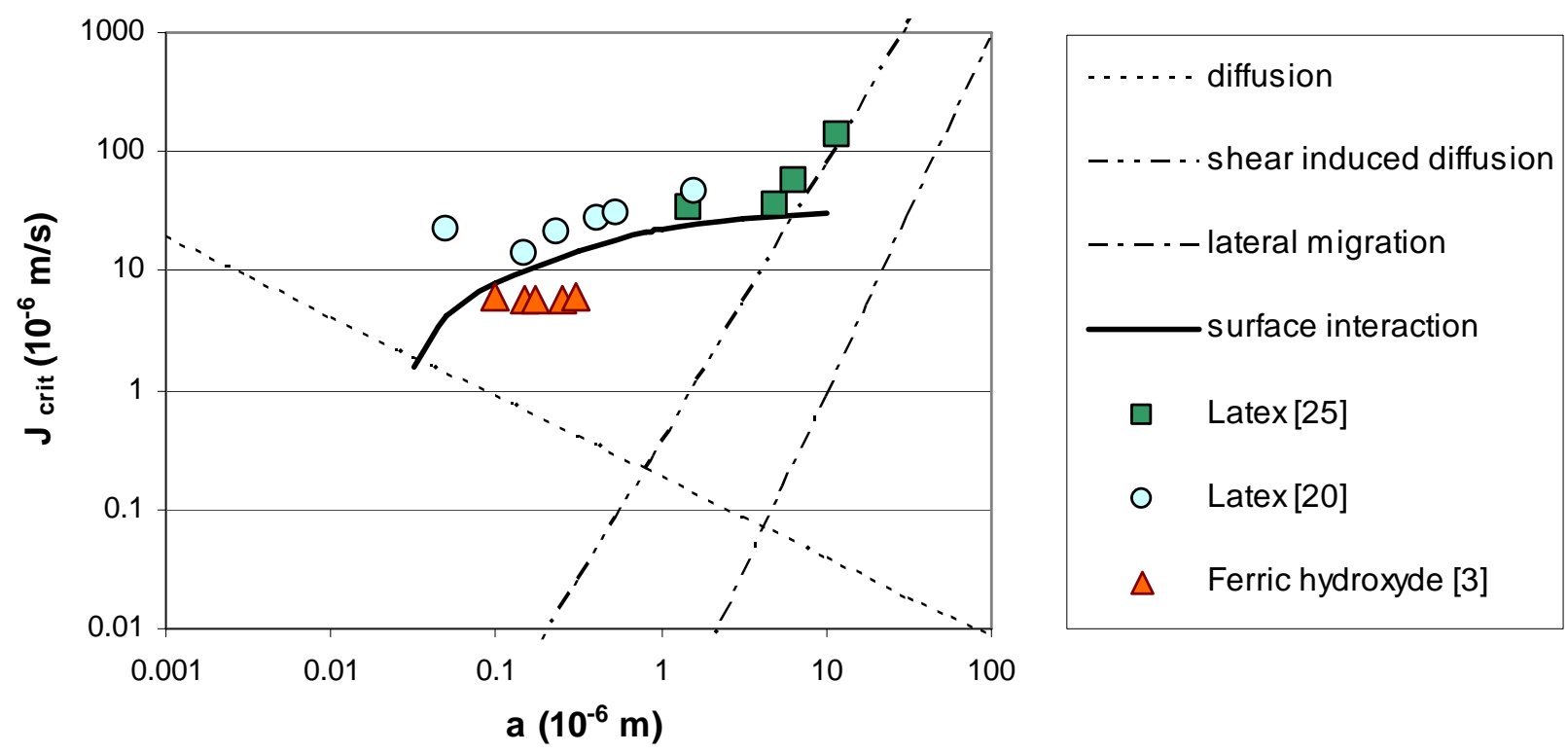
Figure 4. Forms of critical flux as originally defined by Field et al [8]

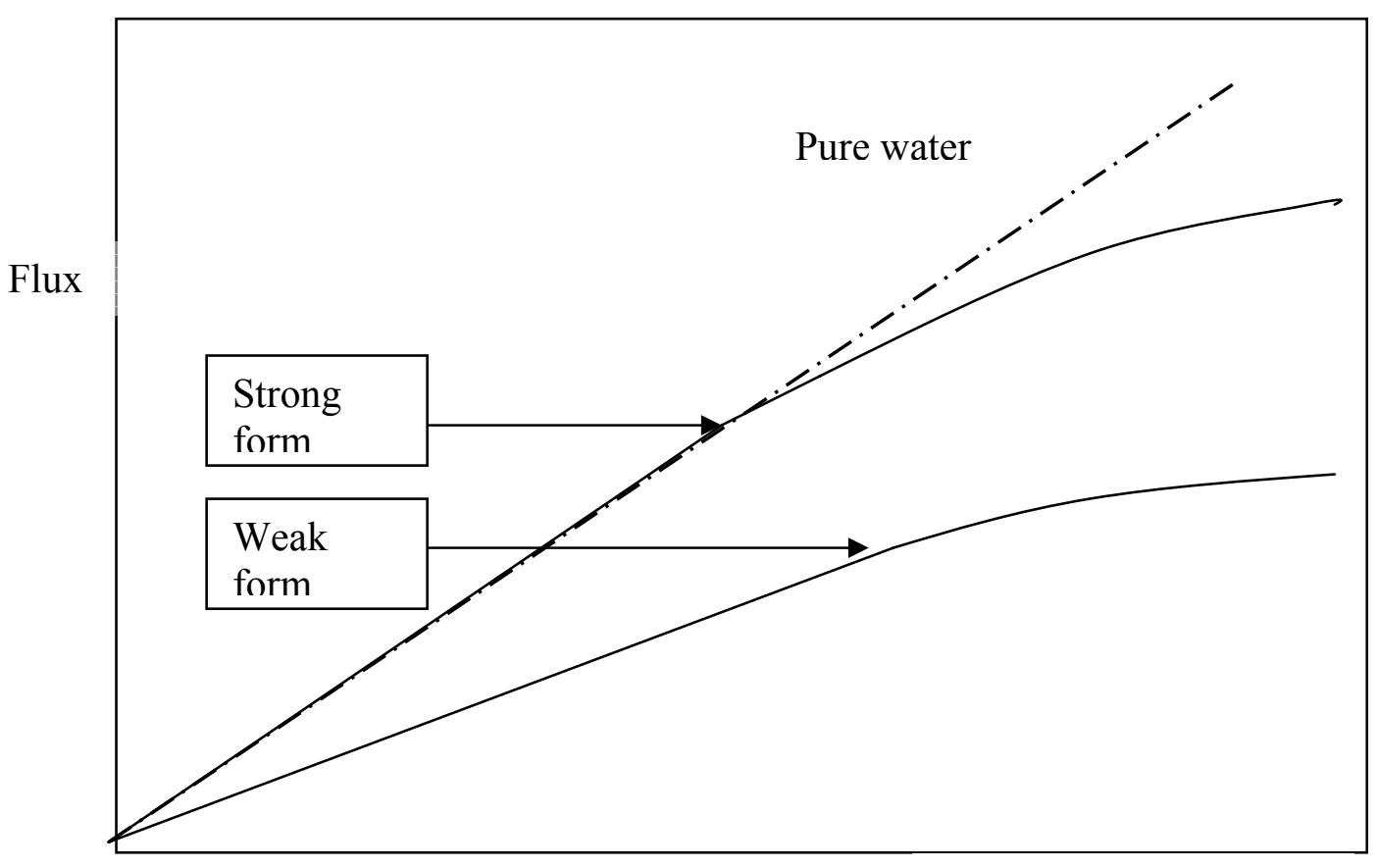

TMP 
Figure 5. Relationship between different critical flux definitions for three types of fouling behaviour. Only for the UF of macromolecules is the osmotic pressure term potentially significant.

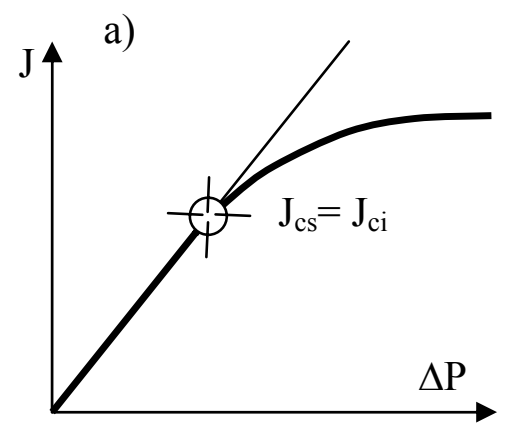

$\mathrm{R}_{\mathrm{ads}}$ insignificant

$\mathrm{R}_{\mathrm{rev}}$ insignificant

$\mathrm{R}_{\text {irrev }}$ significant

(П insignificant)

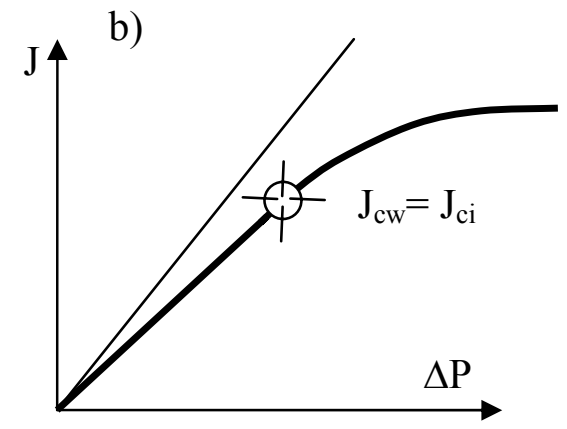

$\mathrm{R}_{\mathrm{ads}} \quad$ significant

$\mathrm{R}_{\mathrm{rev}}$ insignificant

$\mathrm{R}_{\text {irrev }}$ significant

(П insignificant)

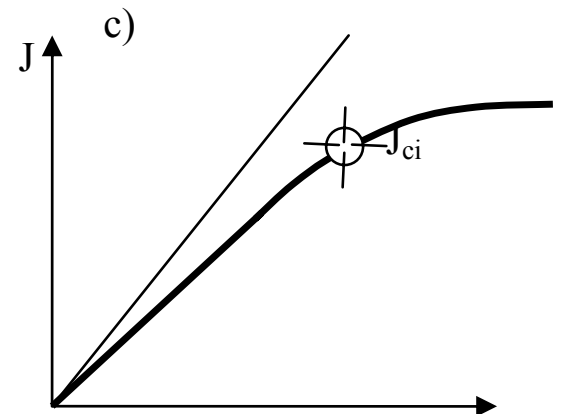

$\mathrm{R}_{\mathrm{ads}}$ significant

$\mathrm{R}_{\text {rev }}$ significant

$\mathrm{R}_{\text {irrev }}$ significant

(П possibily significant after $\mathrm{J}_{\mathrm{ci}}$ ) 
Figure 6. Flux-TMP profiles for lactic acid fermentation broth [16]
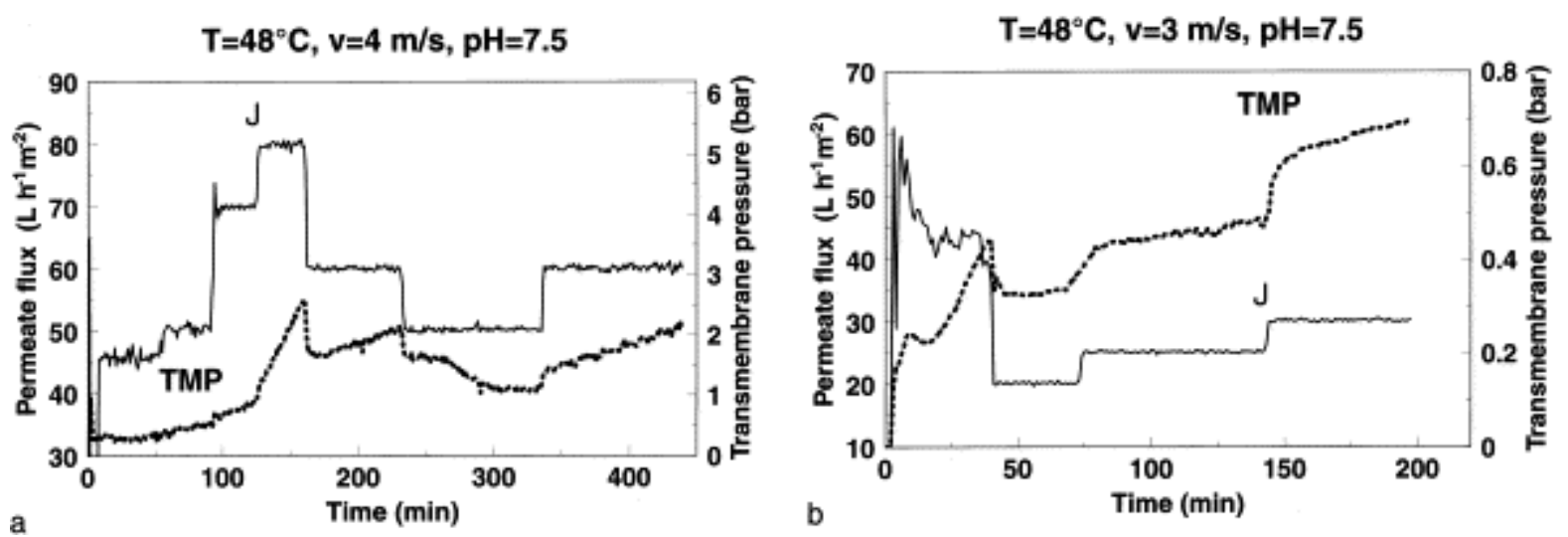
Figure 7. Flux-TMP relationship for lactic acid fermentation broth with a ceramic MF membrane [17]

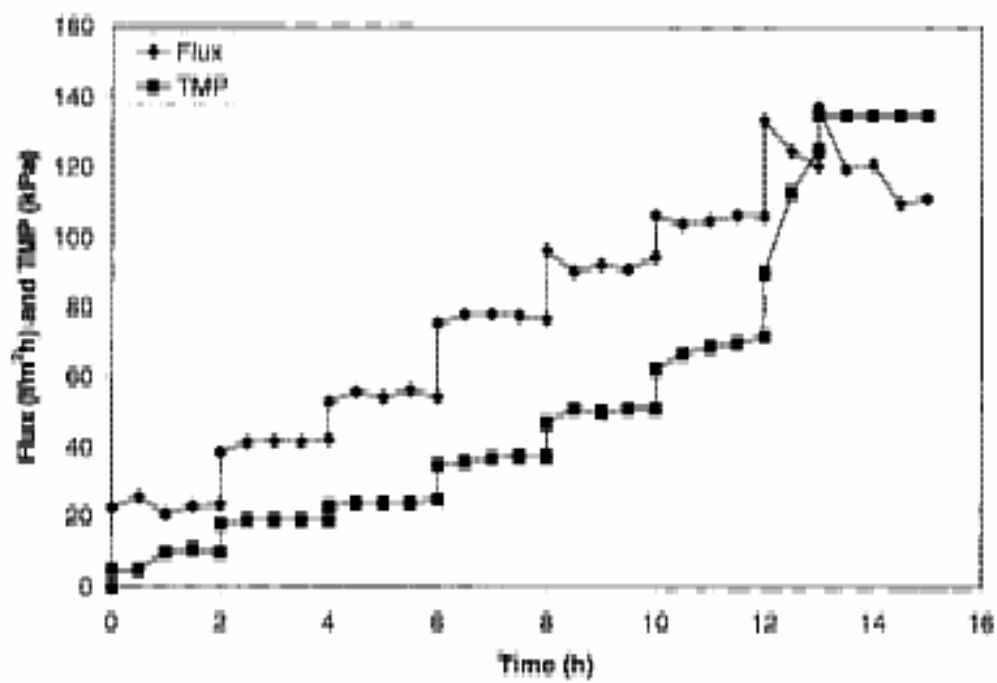

(a)

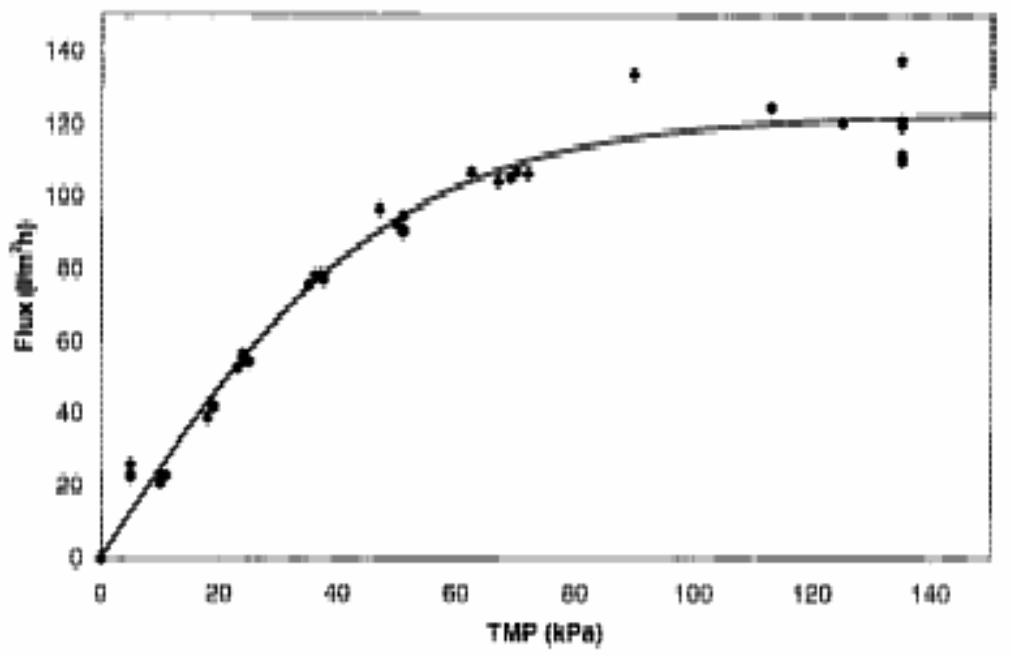

(b) 
Figure 8. The absolute increase in transmembrane pressure between the two points is plotted as a function of the increasing flux. The total transmembrane pressure is also shown $(0.15 \% \mathrm{BSA}, \mathrm{pH}$ 9.7, $\operatorname{Re} 248$ ). Source Figure 7 of [10]. (It is noted that the original caption in [10] $\mathrm{h} \quad \mathrm{s}$ an error, there should not have been a cross-reference to another Figure.)

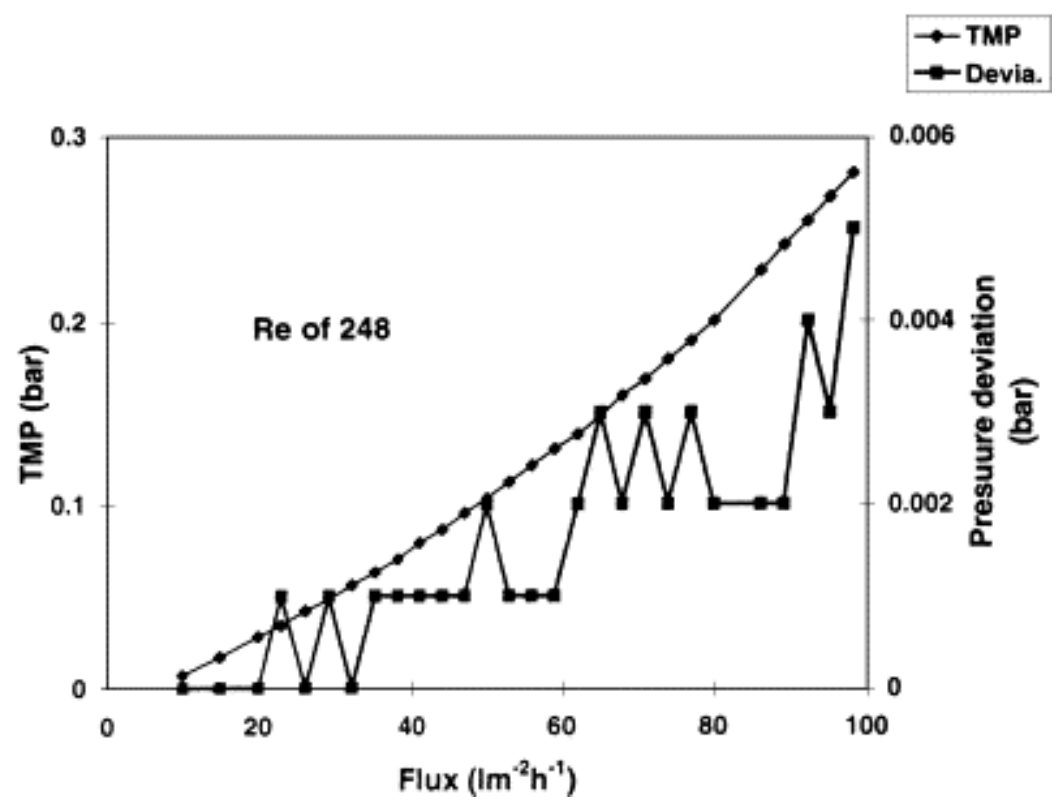


Figure 9. Pressure step used for an accurate determination of critical flux. Comparison of permeate flux obtained in step 4 and 1 allow to conclude at the fouling irreversibility in pressure step 3 [23].
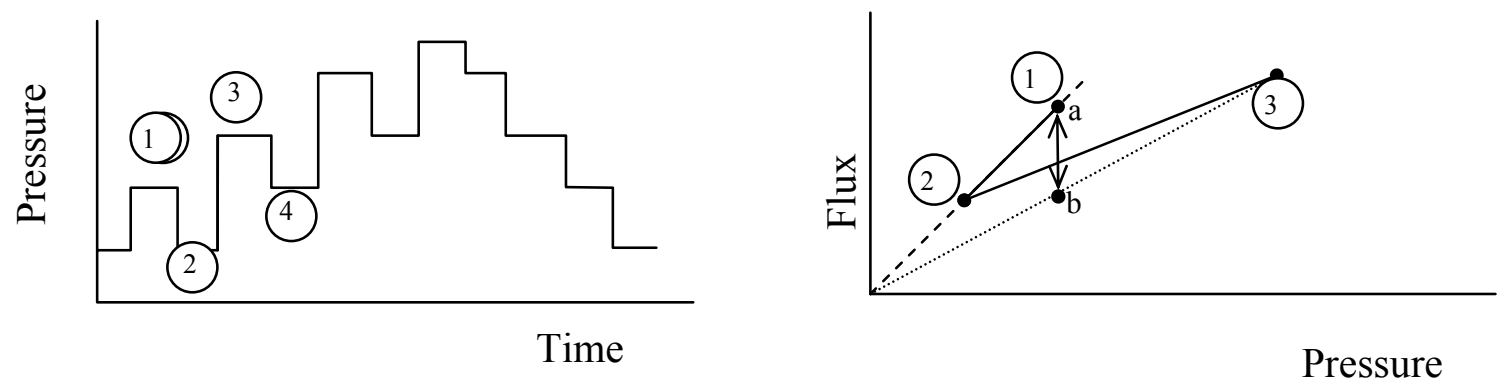
Figure 10. Relationship between applied flux and trans-membrane pressure according filtration procedure in Fig. 8 for water (circle) and PVC latex : points $\mathrm{c}$ and $\mathrm{d}$ corresponds to the range of critical flux (first irreversible fouling) [23].

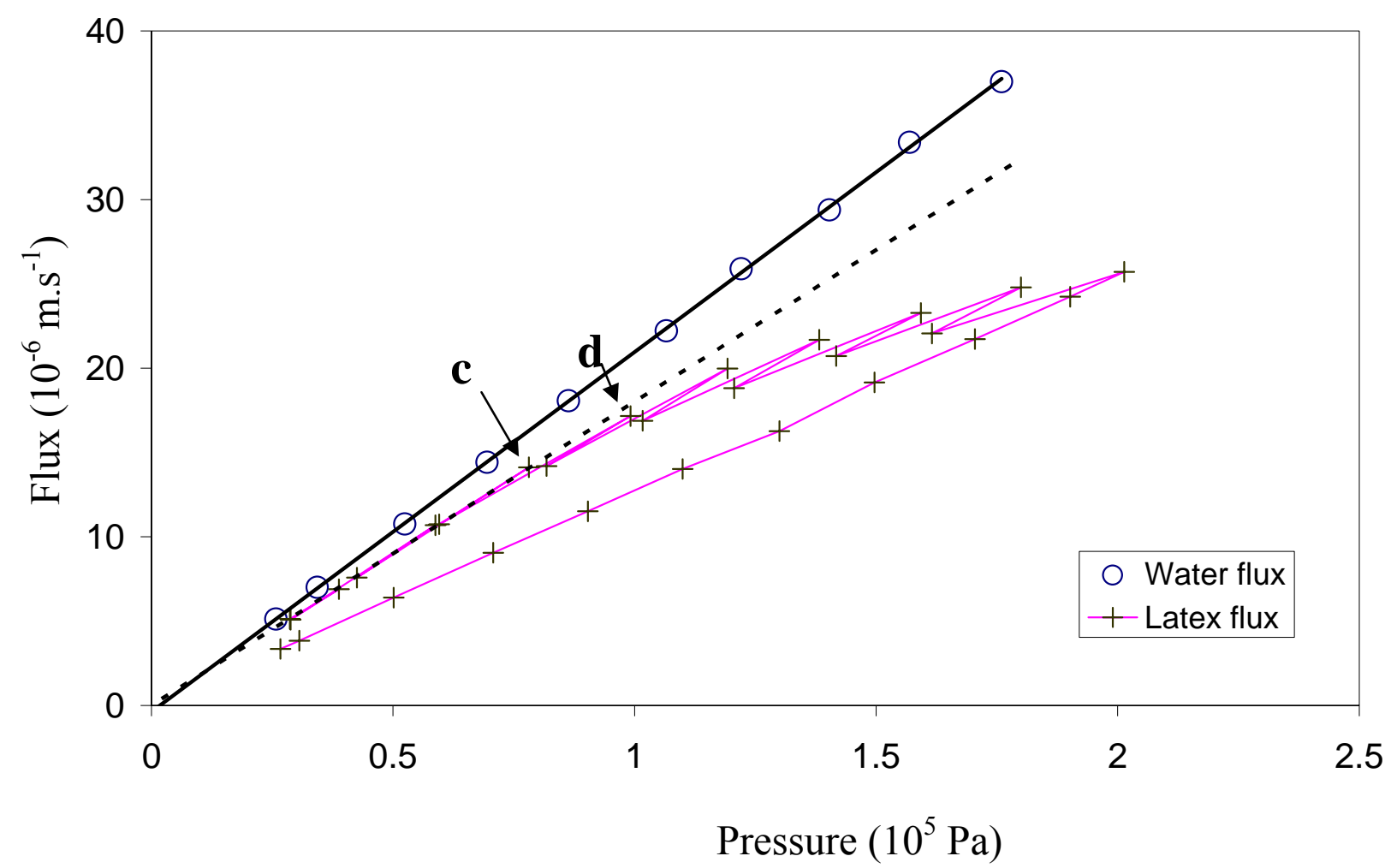


Figure 11. Reversibility of activated sludge fouling [12]

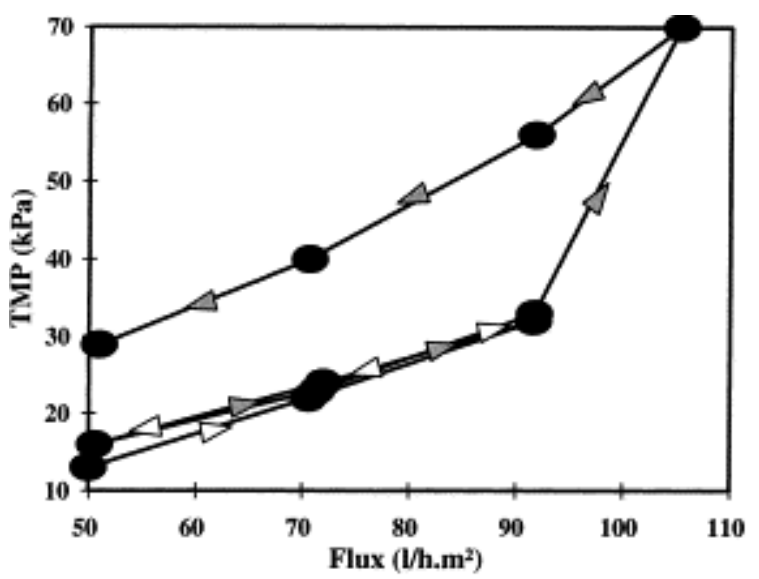


Figure 12. Particle deposition images ((a)-(d)) and the flux and cross-flow conditions (e) in filtration of $11.9 \mu \mathrm{m}$ latex particles. The time when the images were taken is denoted by the vertical broken lines in (e). [24]

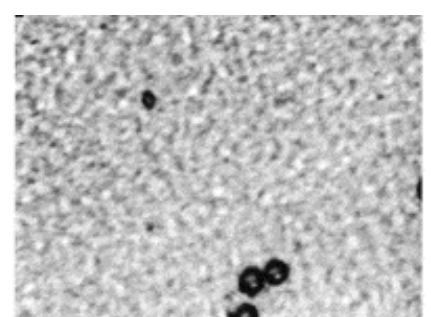

(a) $18 \mathrm{mins}$

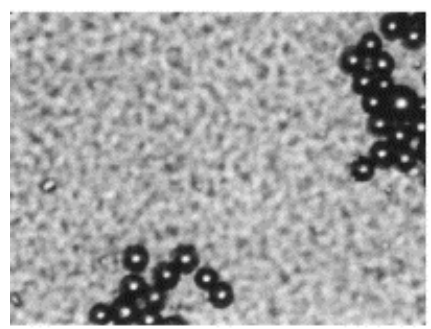

(c) 35 mins

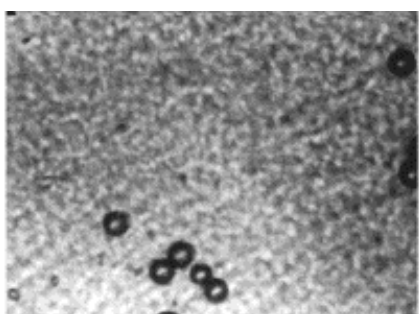

(b) 28.5 mins

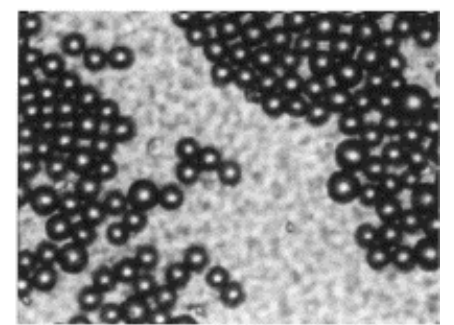

(d) 40 mins

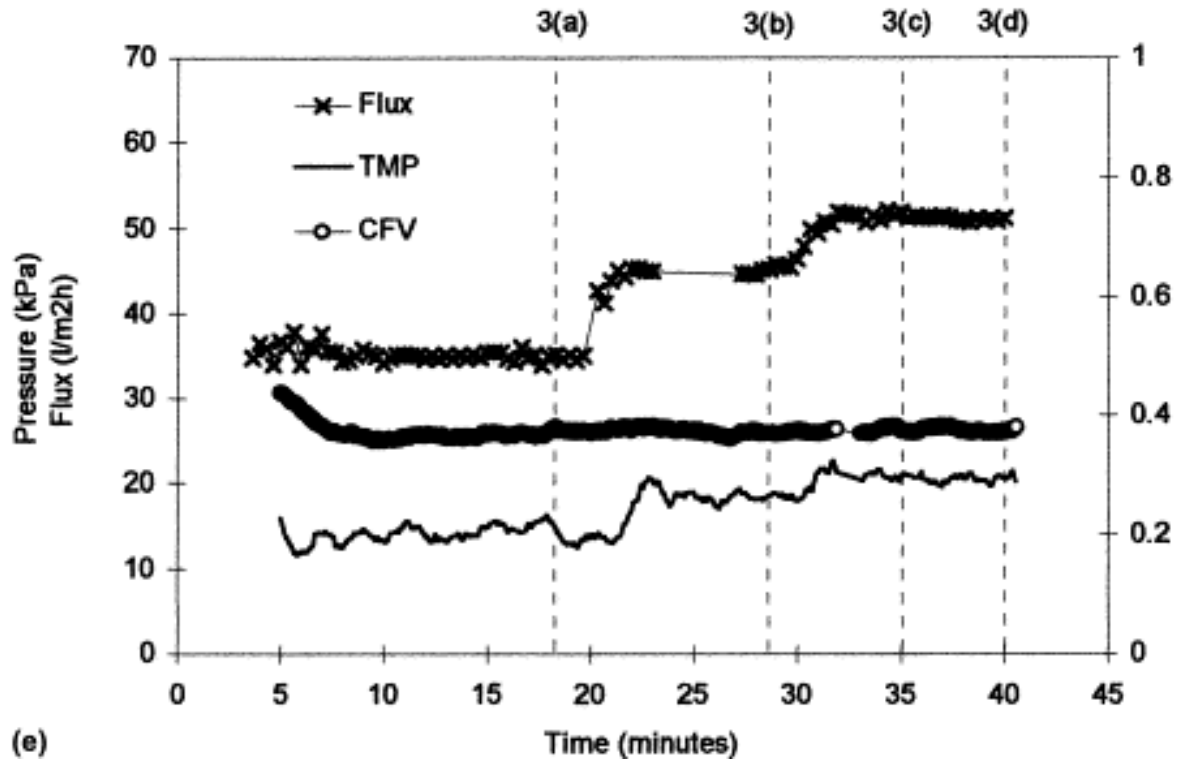

올 
Figure 13. TMP-Flux profile for various membrane pore sizes [34]

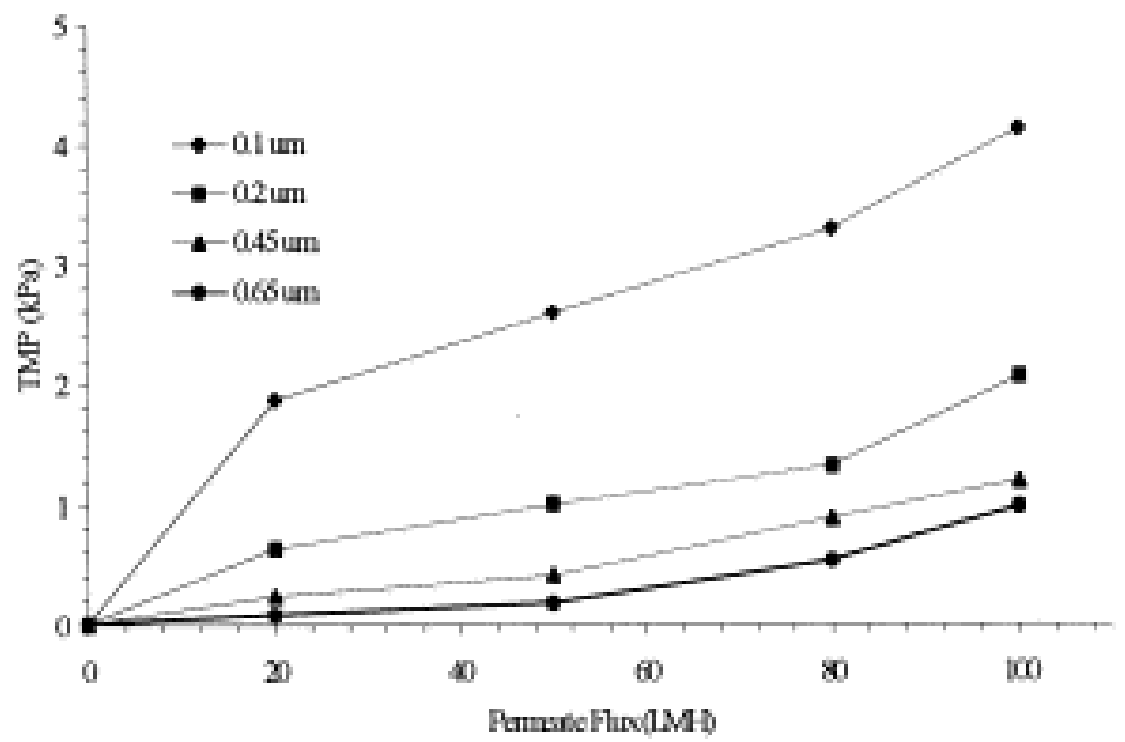


Figure 14. Differences in fouling rate observed with flux stepping [27]

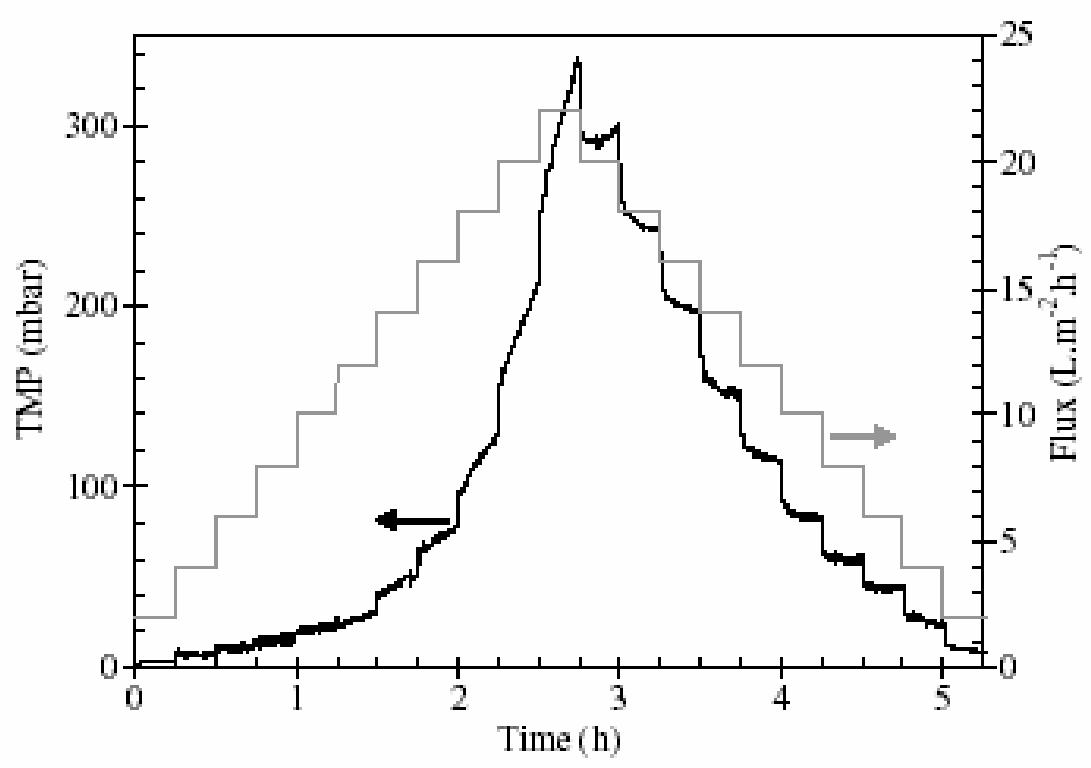


Figure 15. Effect of the $\mathrm{pH}$ on the critical flux obtained during flux stepping, experiments using 0,1 wt.\% solutions BSA. A minimum is observed near the IEP of BSA [42]

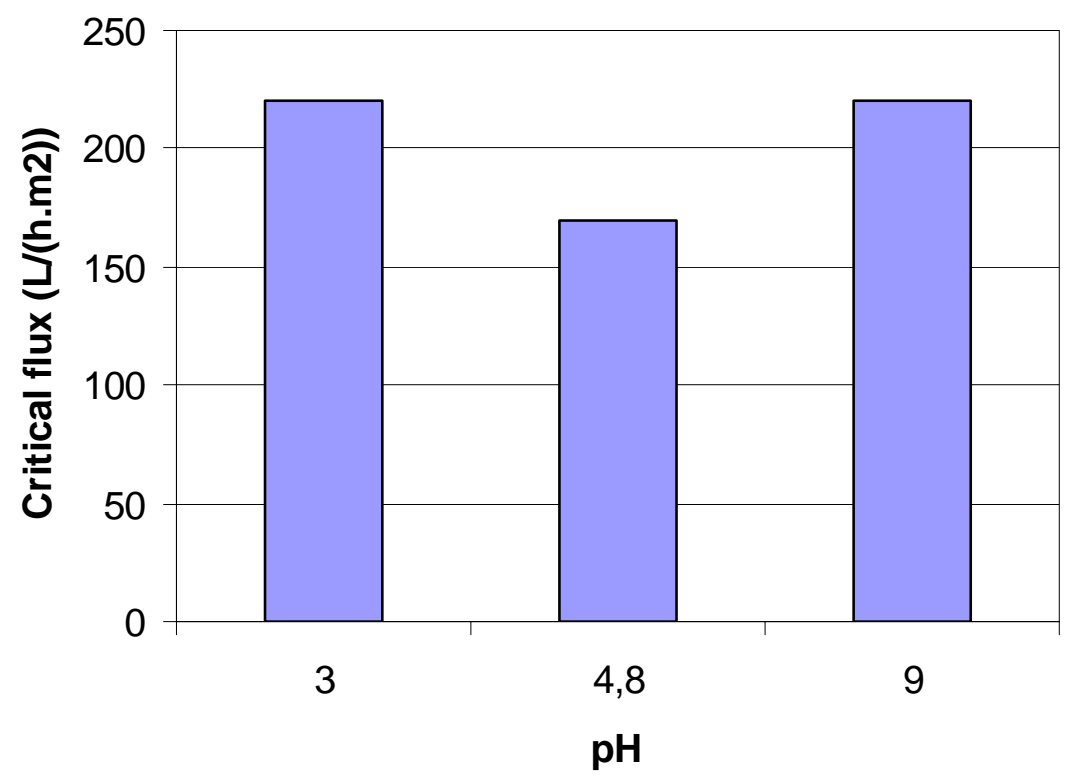


Figure 16. Effect of activated sludge feed concentration on the critical flux [67]

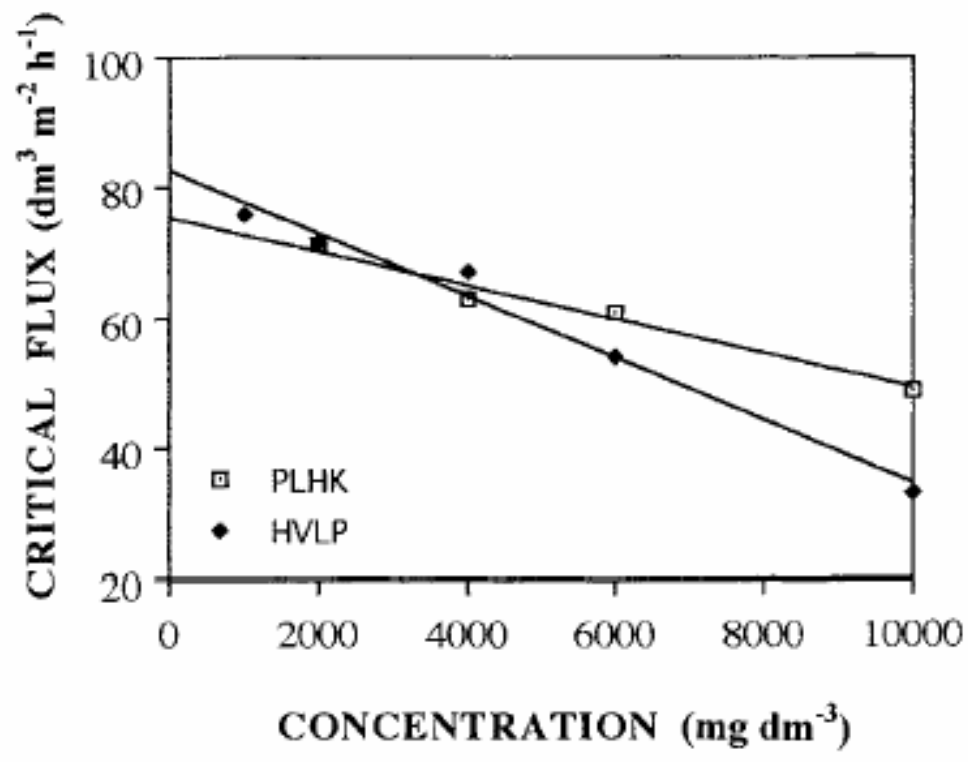


Figure 17. Effect of particles size on the critical flux obtained with latex particles (symbols). These experiments are compared to simulation showing a minimum in critical flux for $100 \mathrm{~nm}$ particles [73].

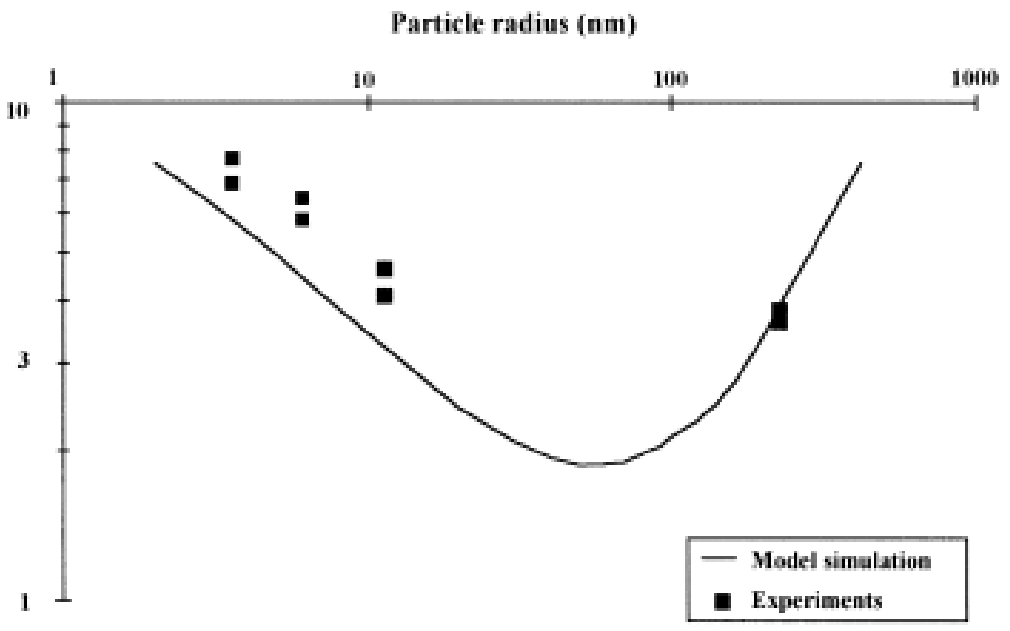

Critical flux $(\mu \mathrm{m} / \mathrm{s})$ 
Figure 18. Critical flux plotted against the walll shear stress. Filtration of skimmed milk realised on a $0.1 \mu \mathrm{m}$ Kerasep membrane [51]

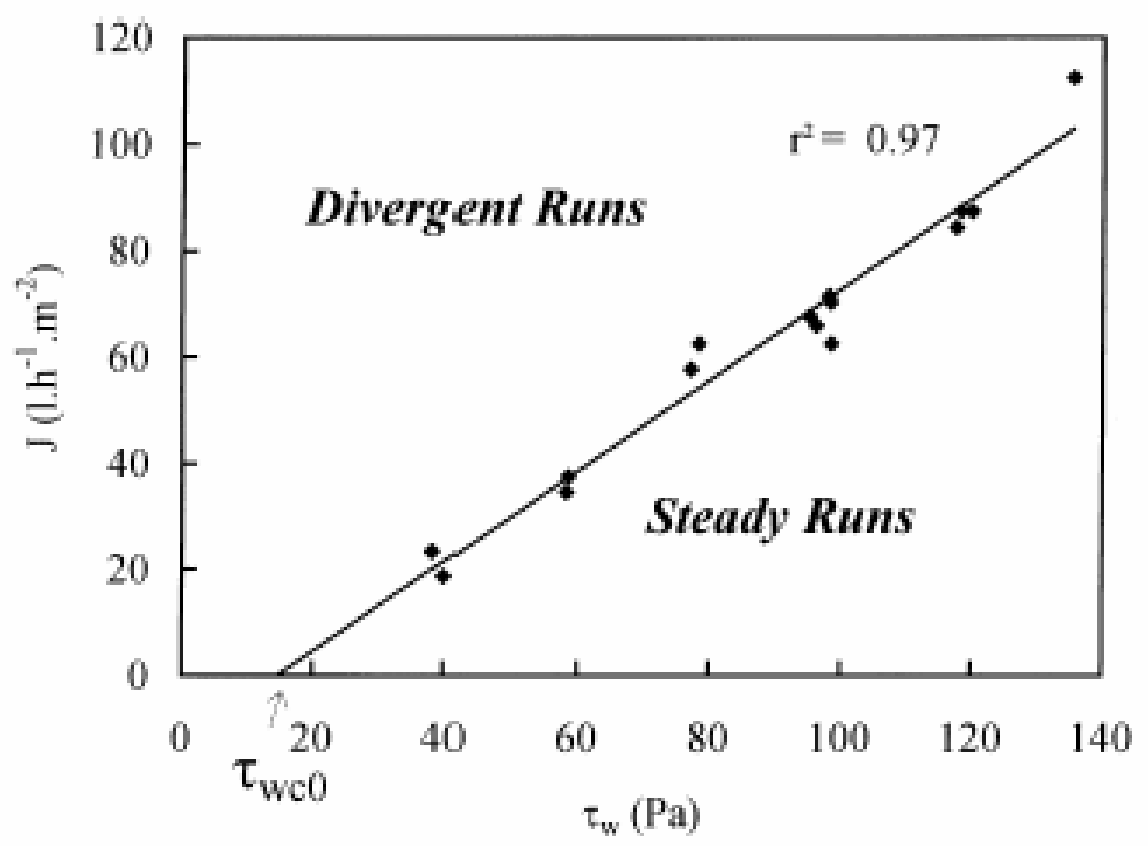


Figure 19. Spatial distribution of extra polymeric substances (EPS) and water flux along a membrane channel (Cho and Fane 2002 [62]). Illustrations of the distribution of a critical flux along the membrane surface.

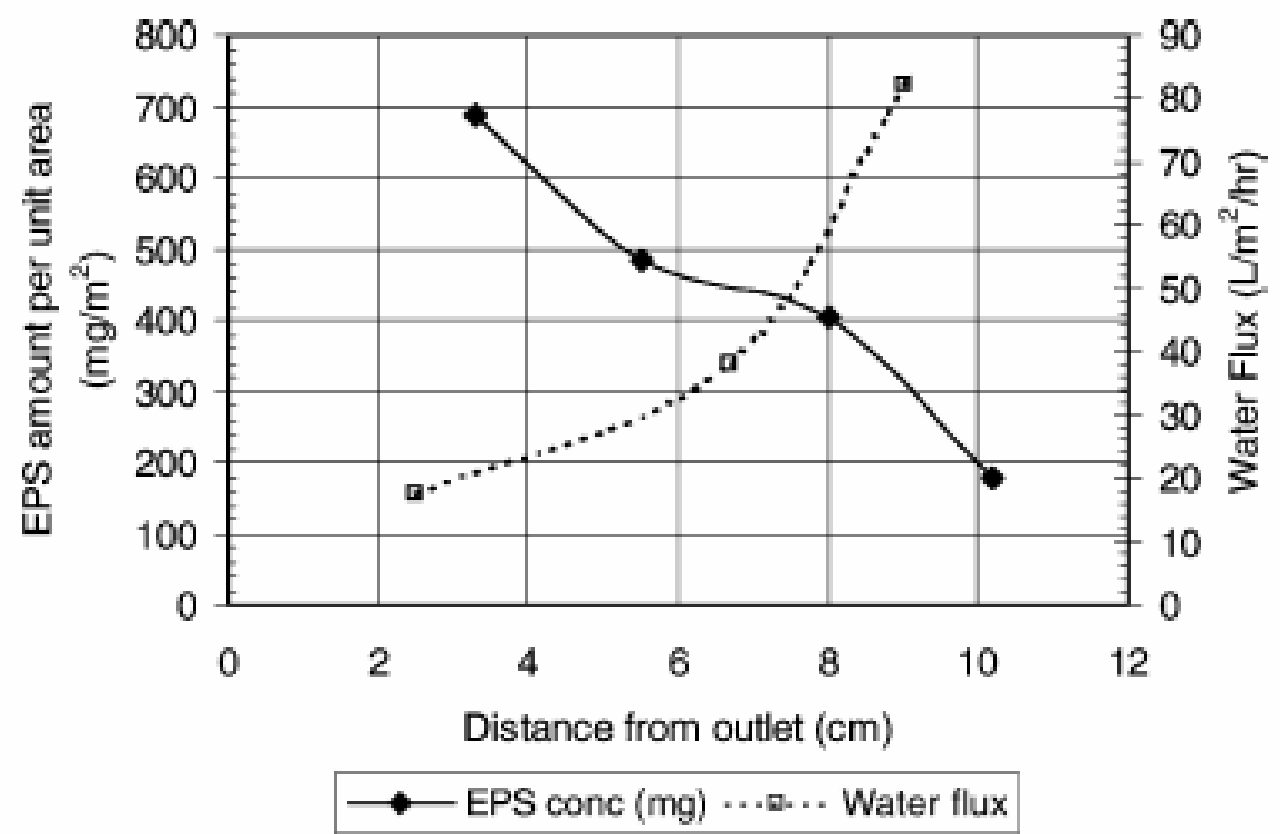


Figure 20. Filtration of a binary mixture of proteins. A minimum of observed rejection in the smaller protein is observed when critical flux is reached [41].

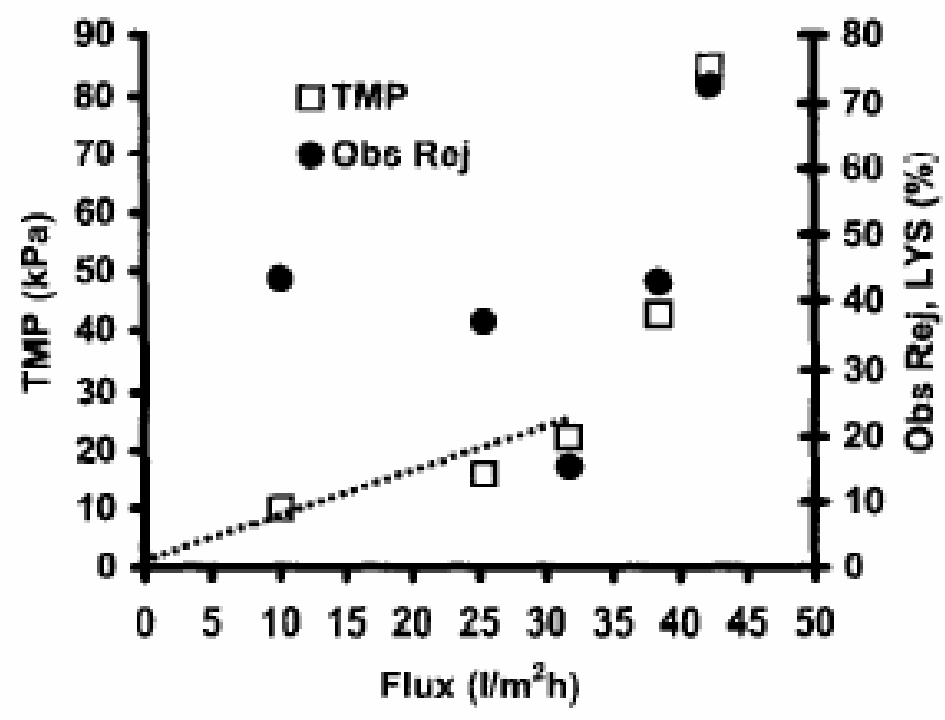


Figure 21. Modelling of the colloid volume fraction near the membrane surface (at $\mathrm{z}=0$ ) and along the membrane channel (entrance at $\mathrm{x}=0$ ). A deposit forms at a critical volume fraction (around 0.5 ). For a flux above the critical flux, a zone of the membrane surface located at the outlet of the membrane channel is covered by the deposit [74].

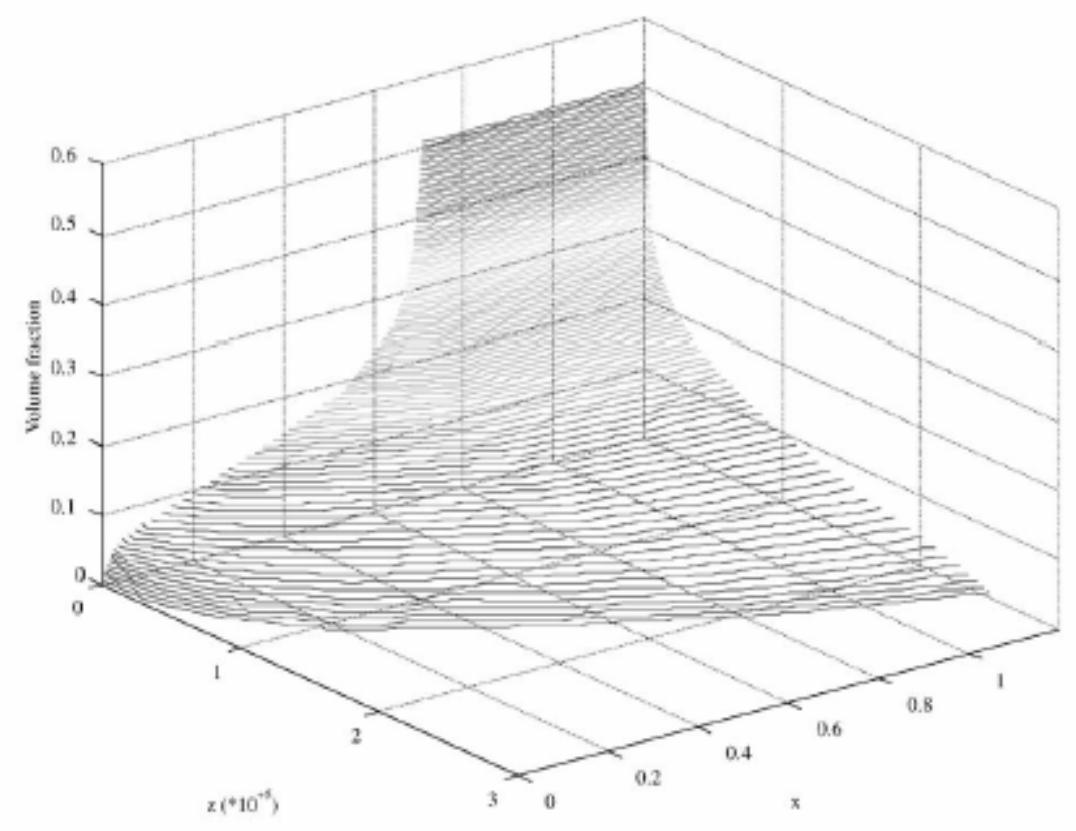


Figure 22. Effect of filtration velocity on the particle trajectories for charged colloids (1) $V f=0.001$ $\mathrm{m} / \mathrm{s}$, (2) $V f=0.01 \mathrm{~m} / \mathrm{s}$, (3) $V f=0.05 \mathrm{~m} / \mathrm{s}$. Filtration conditions (3) is above the critical flux. [94]

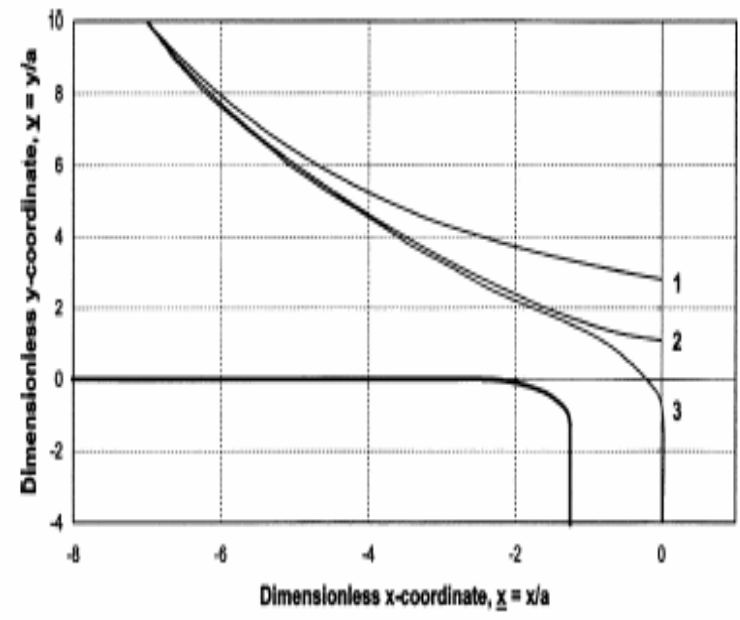




\section{References}

\section{Reference List}

[1] A.S. Michaels, New Separation Technique for the CPI, Chem.Eng.Proc., 64 (1968) 3142 .

[2] M.C. Porter, Concentration polarisation with membrane ultrafiltration., Industrial Engineering Chemical Production, Research and Developpement., 11 (1972) 234-245.

[3] R.D. Cohen, R.F. Probstein, Colloidal Fouling of Revers Osmosis Membranes, Journal of Colloid and Interface Science, 114 (1986) 194-207.

[4] R.M. Mcdonogh, A.G. Fane and C.J.D. Fell, Charge effects in the cross-flow filtration of colloids and particulates, Journal of Membrane Science, 43 (1989) 69-85.

[5] G. Belfort, R.H. Davis and A.L. Zydney, The behavior of suspensions and macromolecular solutions in crossflow microfiltration, Journal of Membrane Science, 96 (1994) 1-58.

[6] P. Bacchin, Formation et résistance au transfert d'un dépot de colloides sur une membrane d'ultrafiltration., 1994) .

[7] P. Bacchin, P. Aimar and V. Sanchez, Model for colloidal fouling of membranes, Aiche Journal, 41 (1995) 368-377.

[8] R.W. Field, D. Wu, J.A. Howell and B.B. Gupta, Critical flux concept for microfiltration fouling, Journal of Membrane Science, 100 (1995) 259-272.

[9] J.A. Howell, Sub-critical flux operation of microfiltration, Journal of Membrane Science, 107 (1995) 165-171.

[10] D.X. Wu, J.A. Howell and R.W. Field, Critical flux measurement for model colloids, Journal of Membrane Science, 152 (1999) 89-98.

[11] L. Defrance, M.Y. Jaffrin, Comparison between filtrations at fixed transmembrane pressure and fixed permeate flux: application to a membrane bioreactor used for wastewater treatment, Journal of Membrane Science, 152 (1999) 203-210.

[12] L. Defrance, M.Y. Jaffrin, Reversibility of fouling formed in activated sludge filtration, Journal of Membrane Science, 157 (1999) 73-84.

[13] Y.K. Benkahla, A. Ould-Dris, M.Y. Jaffrin and D. Si-Hassen, Cake growth mechanism in cross-flow microfiltration of mineral suspensions, Journal of Membrane Science, 98 (1995) 107-117.

[14] G. Gesan-Guiziou, R.J. Wakeman and G. Daufin, Stability of latex crossflow filtration: cake properties and critical conditions of deposition, Chemical Engineering Journal, 85 (2002) 27-34. 
[15] B. Fradin, R.W. Field, Crossflow microfiltration of magnesium hydroxide suspensions: determination of critical fluxes, measurement and modelling of fouling., Separation and Purification Technology, 16 (1999) 25-45.

[16] S. Milcent, H. Carrere, Clarification of lactic acid fermentation broths, Separation and Purification Technology, 22-3 (2001) 393-401.

[17] A. Persson, A.S. Jonsson and G. Zacchi, Separation of lactic acid-producing bacteria from fermentation broth using a ceramic microfiltration membrane with constant permeate flow, Biotechnology and Bioengineering, 72 (2001) 269-277.

[18] V. Chen, A.G. Fane, S. Madaeni and I.G. Wenten, Particle deposition during membrane filtration of colloids: Transition between concentration polarization and cake formation, Journal of Membrane Science, 125 (1997) 109-122.

[19] G. Gesan-Guiziou, G. Daufin and E. Boyaval, Critical stability conditions in skimmed milk crossflow microfiltration: impact on operating modes, Lait, 80 (2000) 129-138.

[20] D.Y. Kwon, S. Vigneswaran, A.G. Fane and R. Ben aim, Experimental determination of critical flux in cross-flow microfiltration, Separation and Purification Technology, 19 (2000) 169-181.

[21] M. Manttari, M. Nystrom, Critical flux in NF of high molar mass polysaccharides and effluents from the paper industry, Journal of Membrane Science, 170 (2000) 257-273.

[22] S. Metsamuuronen, J. Howell and M. Nystrom, Critical flux in ultrafiltration of myoglobin and baker's yeast, Journal of Membrane Science, 196 (2002) 13-25.

[23] B. Espinasse, P. Bacchin and P. Aimar, On an experimental method to measure critical flux in ultrafiltration, Desalination, 146 (2002) 91-96.

[24] H. Li, A.G. Fane, H.G.L. Coster and S. Vigneswaran, Direct observation of particle deposition on the membrane surface during crossflow microfiltration, Journal of Membrane Science, 149 (1998) 83-97.

[25] H. Li, A.G. Fane, H.G.L. Coster and S. Vigneswaran, An assessment of depolarisation models of crossflow microfiltration by direct observation through the membrane, Journal of Membrane Science, 172 (2000) 135-147.

[26] W.R. Bowen, T.A. Doneva and H.-B. Yin, Separation of humic acid from a model surface water with PSU/SPEEK blend UF/NF membranes, Journal of Membrane Science, 206 (2002) 417-429.

[27] P. Le Clech, B. Jefferson, I.S. Chang and S.J. Judd, Critical flux determination by the flux-step method in a submerged membrane bioreactor, Journal of Membrane Science, 227 (2003) 81-93.

[28] B. Jefferson, A. Brookes, P. Le Clech and S.J. Judd, Methods for understanding organic fouling in MBRs, Water Science and Technology, 49 (2004) 237-244.

[29] J.A. Howell, Sub-critical flux operation of microfiltration, Journal of Membrane Science, 107 (1995) 165-171. 
[30] P. Bacchin, P. Aimar and V. Sanchez, Influence of surface interaction on transfer during colloid ultrafiltration, Journal of Membrane Science, 115 (1996) 49-63.

[31] S.S. Madaeni, Rejection in pumping permeate microfiltration, Process Safety and Environmental Protection, 79 (2001) 352-356.

[32] I.H. Huisman, E. Vellenga, G. Tragardh and C. Tragardh, The influence of the membrane zeta potential on the critical flux for crossflow microfiltration of particle suspensions, Journal of Membrane Science, 156 (1999) 153-158.

[33] B. Espinasse, Approche théorique et expérimentale de la filtration tangentielle de colloïdes : flux critique et colmatage., 2003) .

[34] D.Y. Kwon, S. Vigneswaran, Influence of particle size and surface charge on critical flux of crossflow microfiltration, Water Science and Technology, 38 (1998) 481-488.

[35] S. Vigneswaran, D.Y. Kwon, H.H. Ngo and J.Y. Hu, Improvement of microfiltration performance in water treatment: is critical flux a viable solution?, Water Science and Technology, 41 (2000) 309-315.

[36] C. Cabassud, S. Laborie, L. Durand-Bourlier and J.M. Laine, Air sparging in ultrafiltration hollow fibers: relationship between flux enhancement, cake characteristics and hydrodynamic parameters, Journal of Membrane Science, 181 (2001) 57-69.

[37] M. Hamachi, M. Mietton-Peuchot, Analysis of deposit behaviour in crossflow microfiltration by means of thickness measurement, Chemical Engineering Journal, 86 (2002) 251-257.

[38] D.Y. Kwon, S. Vigneswaran, H.H. Ngo and H.S. Shin, An enhancement of critical flux in crossflow microfiltration with a pretreatment of floating medium flocculator/prefilter, Water Science and Technology, 36 (1997) 267-274.

[39] J.A. Howell, T.C. Arnot, H.C. Chua, P. Godino, D. Hatziantoniou and S. Metsamuuronen, Controlled flux behaviour of membrane processes, Macromolecular Symposia, 188 (2002) 23-35.

[40] H.K. Vyas, R.J. Bennett and A.D. Marshall, Performance of crossflow microfiltration during constant transmembrane pressure and constant flux operations, International Dairy Journal, 12 (2002) 473-479.

[41] R. Chan, V. Chen and M.P. Bucknall, Ultrafiltration of protein mixtures: measurement of apparent critical flux, rejection performance, and identification of protein deposition, Desalination, 146 (2002) 83-90.

[42] R. Chan, V. Chen, The effects of electrolyte concentration and $\mathrm{pH}$ on protein aggregation and deposition: critical flux and constant flux membrane filtration, Journal of Membrane Science, 185 (2001) 177-192.

[43] V. Chen, Performance of partially permeable microfiltration membranes under low fouling conditions, Journal of Membrane Science, 147 (1998) 265-278. 
[44] J.M.O. De Zarate, C. Rincon and J.I. Mengual, Concentration of bovine serum albumin aqueous solutions by membrane distillation, Separation Science and Technology, 33 (1998) 283-296.

[45] E. Aoustin, A.I. Schafer, A.G. Fane and T.D. Waite, Ultrafiltration of natural organic matter, Separation and Purification Technology, 22-3 (2001) 63-78.

[46] A. Seidel, M. Elimelech, Coupling between chemical and physical interactions in natural organic matter (NOM) fouling of nanofiltration membranes: implications for fouling control, Journal of Membrane Science, 203 (2002) 245-255.

[47] W. Yuan, A. Kocic and A.L. Zydney, Analysis of humic acid fouling during microfiltration using a pore blockage-cake filtration model, Journal of Membrane Science, 198 (2002) 51-62.

[48] S. Chang, A.G. Fane, Characteristics of microfiltration of suspensions with inter-fiber two-phase flow, Journal of chemical technology and biotechnology, 75 (2000) 533540 .

[49] H.W. Sur, Z.F. Cui, Experimental study on the enhancement of yeast microfiltration with gas sparging, Journal of chemical technology and biotechnology, 76 (2001) 477484.

[50] O. Al Akoum, L.H. Ding and M.Y. Jaffrin, Microfiltration and ultrafiltration of UHT skim milk with a vibrating membrane module, Separation and Purification Technology, 28 (2002) 219-234.

[51] G. Gesan-Guiziou, E. Boyaval and G. Daufin, Critical stability conditions in crossflow microfiltration of skimmed milk: transition to irreversible deposition, Journal of Membrane Science, 158 (1999) 211-222.

[52] G. Gesan-Guiziou, G. Daufin, E. Boyaval and O. Le Berre, Wall shear stress: effective parameter for the characterisation of the cross-flow transport in turbulent regime during skimmed milk microfiltration, Lait, 79 (1999) 347-354.

[53] A.S. Grandison, W. Youravong and M.J. Lewis, Hydrodynamic factors affecting flux and fouling during ultrafiltration of skimmed milk, Lait, 80 (2000) 165-174.

[54] W. Youravong, A.S. Grandison and M.J. Lewis, Effect of hydrodynamic and physicochemical changes on critical flux of milk protein suspensions, Journal of Dairy Research, 69 (2002) 443-455.

[55] H. Chapman, S. Vigneswaran, H.H. Ngo, S. Dyer and R. Ben aim, Pre-flocculation of secondary treated wastewater in enhancing the performance of microfiltration, Desalination, 146 (2002) 367-372.

[56] P. Choksuchart, M. Heran and A. Grasmick, Ultrafiltration enhanced by coagulation in an immersed membrane system, Desalination, 145 (2002) 265-272.

[57] L. Vera, R. Villarroel-Lopez, S. Delgado and S. Elmaleh, Cross-flow microfiltration of biologically treated wastewater, Desalination, 114 (1997) 65-75. 
[58] L. Vera, R. Villarroel, S. Delgado and S. Elmaleh, Can microfiltration of treated wastewater produce suitable water for irrigation?, Water Science and Technology, 38 (1998) 395-403.

[59] H. Carrere, F. Blaszkowa and H. Roux de Balmann, Modelling the microfiltration of lactic acid fermentation broths and comparison of operating modes, Desalination, 145 (2002) 201-206.

[60] E.H. Bouhabila, R. Ben aim and H. Buisson, Microfiltration of activated sludge using submerged membrane with air bubbling (application to wastewater treatment), Desalination, 118 (1998) 315-322.

[61] S. Chang, A.G. Fane, Filtration of biomass with laboratory-scale submerged hollow fibre modules - effect of operating conditions and module configuration, Journal of chemical technology and biotechnology, 77 (2002) 1030-1038.

[62] B.D. Cho, A.G. Fane, Fouling transients in nominally sub-critical flux operation of a membrane bioreactor, Journal of Membrane Science, 209 (2002) 391-403.

[63] K.H. Choo, C.H. Lee, Hydrodynamic behavior of anaerobic biosolids during crossflow filtration in the membrane anaerobic bioreactor, Water Research, 32 (1998) 3387-3397.

[64] A.G. Fane, S. Chang and E. Chardon, Submerged hollow fibre membrane module design options and operational considerations, Desalination, 146 (2002) 231-236.

[65] M. Gander, B. Jefferson and S. Judd, Aerobic MBRs for domestic wastewater treatment: a review with cost considerations, Separation and Purification Technology, 18 (2000) 119-130.

[66] B. Jefferson, A.L. Laine, S.L. Judd and T. Stephenson, Membrane bioreactors and their role in wastewater reuse, Water Science and Technology, 41 (2000) 197-204.

[67] S.S. Madaeni, A.G. Fane and D.E. Wiley, Factors influencing critical flux in membrane filtration of activated sludge, Journal of chemical technology and biotechnology, 74 (1999) 539-543.

[68] S. Ognier, C. Wisniewski and A. Grasmick, Characterisation and modelling of fouling in membrane bioreactors, Desalination, 146 (2002) 141-147.

[69] T. Huuhilo, P. Vaisanen, J. Nuortila-Jokinen and M. Nystrom, Influence of shear on flux in membrane filtration of integrated pulp and paper mill circulation water, Desalination, 141 (2001) 245-258.

[70] M. Manttari, J. Nuortila-Jokinen and M. Nystrom, Influence of filtration conditions on the performance of NF membranes in the filtration of paper mill total effluent, Journal of Membrane Science, 137 (1997) 187-199.

[71] P. Aimar, V. Sanchez, A novel approach to transfer limiting phenomena during ultrafiltration of macromolecules, Ind.Eng.Chem.Fundam., 25 (1986) 789-798.

[72] R.W. Field, P. Aimar, Ideal limiting fluxes in ultrafiltration: comparison of various theoretical relationships, Journal of Membrane Science, 80 (1993) 107-115. 
[73] P. Harmant, P. Aimar, Coagulation of colloids in a boundary layer during cross flow filtration, Colloids and Surfaces, 138 (1998) 217-230.

[74] P. Bacchin, D. Si-Hassen, V. Starov, M.J. Clifton and P. Aimar, A unifying model for concentration polarization, gel-layer formation and particle deposition in cross-flow membrane filtration of colloidal suspensions, Chemical Engineering Science, 57 (2002) 77-91.

[75] K.-H. Ahn, K.-G. Song, Application of microfiltration with a novel fouling control method for reuse of wastewater from a large-scale resort complex, Desalination, 129 (2000) 207-216.

[76] P. Bacchin, A possible link between critical and limiting flux for colloidal systems: consideration of critical deposit formation along a membrane, Journal of Membrane Science, 228 (2004) 237-241.

[77] C. Gourgues, P. Aimar, V. Sanchez, C. Cabassud and P. Aptel, Ultrafiltration of bentonite suspensions. Models and applications, 6 (1992) 269-274.

[78] J. Schwinge, P.R. Neal, D.E. Wiley and A.G. Fane, Estimation of foulant deposition across the leaf of a spiral-wound module, Desalination, 146 (2002) 203-208.

[79] S. Chang, A.G. Fane and S. Vigneswaran, Modeling and optimizing submerged hollow fiber membrane modules, Aiche Journal, 48 (2002) 2203-2212.

[80] P. Bacchin, M. Meireles and P. Aimar, Modelling of filtration: from the polarised layer to deposit formation and compaction, Desalination, 145 (2002) 139-146.

[81] A.J. Bromley, R.G. Holdich and I.W. Cumming, Particulate fouling of surface microfilters with slotted and circular pore geometry, Journal of Membrane Science, 196 (2002) 27-37.

[82] S. Kuiper, C.J.M. van Rijn, W. Nijdam, G.J.M. Krijnen and M.C. Elwenspoek, Determination of particle-release conditions in microfiltration: a simple single-particle model tested on a model membrane, Journal of Membrane Science, 180 (2000) 15-28.

[83] B.A. Buffham, I.W. Cumming, Prevention of particles deposition in crossflow microfiltration, Trans IChemE, 73 (1995) 445-454.

[84] A.S. Berman, Laminar flow in channel with porous walls., Journal of Applied Physics, 24 (1953) 1232-1235.

[85] W.R. Bowen, A. Mongruel and P.M. Williams, Prediction of the rate of cross-flow membrane ultrafiltration: A colloidal interaction approach, Chemical Engineering Science, 51 (1996) 4321-4333.

[86] W.R. Bowen, F. Jenner, Dynamic ultrafiltration model for charged colloidal dispersions: A Wigner-Seitz cell approach, Chemical Engineering Science, 50 (1995) 1707-1736.

[87] A.S. Jonsson, B. Jonsson, Ultrafiltration of Colloidal Dispersions--A Theoretical Model of the Concentration Polarization Phenomena, Journal of Colloid and Interface Science, 180 (1996) 504-518. 
[88] S. Bhattacharjee, A.S. Kim and M. Elimelech, Concentration polarization of interacting solute particles in cross-flow membrane filtration, Journal of Colloid and Interface Science, 212 (1999) 81-99.

[89] D.N. Petsev, V.M. Starov and I.B. Ivanov, Concentrated dispersions of charged colloidal particles: Sedimentation, ultrafiltration and diffusion, Colloids and Surfaces aPhysicochemical and Engineering Aspects, 81 (1993) 65-81.

[90] S.P. Palecek, A.L. Zydney, Intermolecular electrostatic interactions and their effect on flux and protein deposition during protein filtration, Biotechnology Progress, 10 (1994) 207-213.

[91] P. Harmant, P. Aimar, Coagulation of colloids retained by porous wall, Aiche Journal, 42 (1996) 3523-3532.

[92] W.R. Bowen, A.N. Filippov, A.O. Sharif and V.M. Starov, A model of the interaction between a charged particle and a pore in a charged membrane surface, Advances in Colloid and Interface Science, 81 (1999) 35-72.

[93] W.R. Bowen, A.O. Sharif, Prediction of optimum membrane design: pore entrance shape and surface potential, Colloids and Surfaces a-Physicochemical and Engineering Aspects, 201 (2002) 207-217.

[94] M.M. Kim, A.L. Zydney, Effect of electrostatic, hydrodynamic, and Brownian forces on particle trajectories and sieving in normal flow filtration, Journal of Colloid and Interface Science, 269 (2004) 425-431.

[95] M.V. Smoluchowski, Mathematical theory of the kinetics of the coagulation of colloidal solutions, Z.Phys.Chem., 92 (1917) 129.

[96] E.J.W. Verwey, J.Th.G. Overbeek, Theory of the stability of lyophobic colloids: the interaction of sol particles having an electric double layer, 1948) .

[97] Z. Adamczyk, T. Dabros, J. Czarnecki and T.G.M. Van de Ven, Particle transfer to solid surfaces, Advances in Colloid and Interface Science, 19 (2005) 183-252.

[98] L. Song, M. Elimelech, Particle Deposition onto a Permeable Surface in Laminar Flow, Journal of Colloid and Interface Science, 173 (1995) 165-180.

[99] T.G.M. Van de Ven, Effects of electrolytes, polymers and polyelectrolytes on particle deposition and detachment, Colloids and Surfaces, 39 (2005) 107-126.

[100]P. Bacchin, P. Aimar, Critical fouling conditions induced by colloidal surface interaction: from causes to consequences, Desalination, 27x (2005) xxx.

[101]P. Bacchin, B. Espinasse and P. Aimar, Distributions of critical flux: modelling, experimental analysis and consequences for cross-flow membrane filtration, Journal of Membrane Science, 250 (2005) 223-234.

[102]P. Bacchin, B. Espinasse and P. Aimar, Distributions of critical flux: modelling, experimental analysis and consequences for cross-flow membrane filtration, Journal of Membrane Science, 250 (2005) 223-234. 
[103]W. Yuan, A. Kocic and A.L. Zydney, Analysis of humic acid fouling during microfiltration using a pore blockage-cake filtration model, Journal of Membrane Science, 198 (2002) 51-62. 